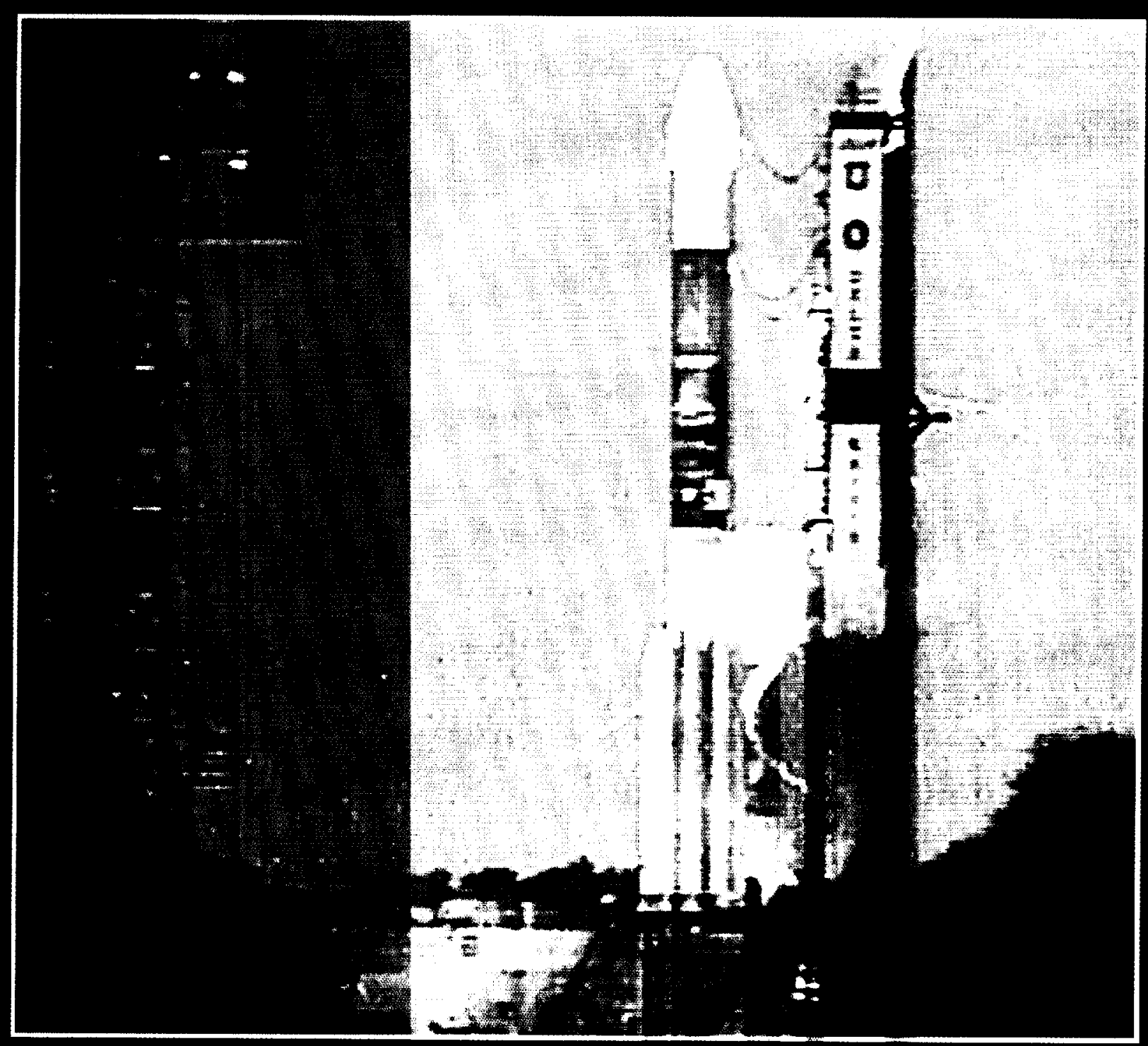

Volume 77

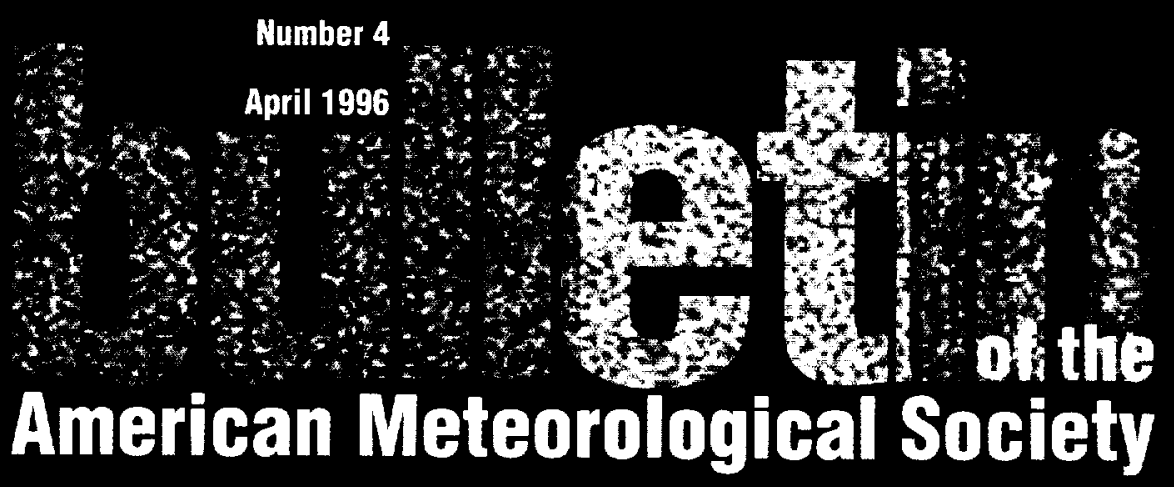





\title{
Workstation-Based Real-Time Mesoscale Modeling Designed for Weather Support to Operations at the Kennedy Space Center and Cape Canaveral Air Station

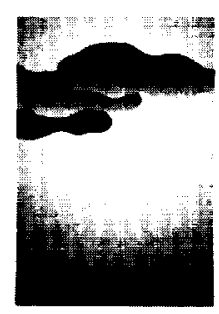

\author{
John Manobianco,,*\# John W. Zack,+ and Gregory E. Taylor*,*
}

\begin{abstract}
This paper describes the capabilities and operational utility of a version of the Mesoscale Atmospheric Simulation System (MASS) that has been developed to support operational weather forecasting at the Kennedy Space Center (KSC) and Cape Canaveral Air Station (CCAS). The implementation of local, mesoscale modeling systems at $\mathrm{KSC} / \mathrm{CCAS}$ is designed to provide detailed short-range $(<24 \mathrm{~h})$ forecasts of winds, clouds, and hazardous weather such as thunderstorms. Short-range forecasting is a challenge for daily operations, and manned and unmanned launches since $\mathrm{KSC} / \mathrm{CCAS}$ is located in central Florida where the weather during the warm season is dominated by mesoscale circulations like the sea breeze.

For this application, MASS has been modified to run on a Stardent 3000 workstation. Workstation-based, realtime numerical modeling requires a compromise between the requirement to run the system fast enough so that the output can be used before expiration balanced against the desire to improve the simulations by increasing resolution and using more detailed physical parameterizations. It is now feasible to run high-resolution mesoscale models such as MASS on local workstations to provide timely forecasts at a fraction of the cost required to run these models on mainframe supercomputers.

MASS has been running in the Applied Meteorology Unit (AMU) at KSC/CCAS since January 1994 for the purpose of system evaluation. In March 1995, the AMU began sending real-time MASS output to the forecasters and meteorologists at CCAS, Spaceflight Meteorology Group (Johnson Space Center, Houston, Texas), and the National Weather Service (Melbourne, Florida). However, MASS is not yet an operational system. The final decision whether to transition MASS for operational use will depend on a combination of forecaster feedback, the AMU's final evaluation results, and the life-cycle costs of the operational system.
\end{abstract}

\section{Introduction}

The National Aeronautics and Space Administration (NASA) and United States Air Force (USAF) have been conducting ground and spaceflight opera-

*ENSCO, Inc., Melbourne, Florida.

'MESO, Inc., Troy, New York.

"Applied Meteorology Unit, NASA/Kennedy Space Center, Kennedy Space Center, Florida.

Corresponding author address: Dr. John Manobianco, ENSCO, Inc., 445 Pineda Court, Melbourne, FL 32940.

E-mail: manobianco@fl.ensco.com

In final form 5 October 1995.

(C1996 American Meteorological Society tions at the Kennedy Space Center (KSC) and Eastern Range at Cape Canaveral Air Station (CCAS) since the early $1960 \mathrm{~s}$. Weather support to operations at $\mathrm{KSC} / \mathrm{CCAS}$ requires detailed forecasts of winds, clouds, ceilings, fog, and hazardous weather such as thunderstorms. Forecasting these parameters for $\mathrm{KSC} / \mathrm{CCAS}$ is a challenging task since the central Florida facilities are located in an environment where there is an absence of significant large-scale dynamical forcing during much of the year. Under these conditions, regional and local factors such as land-water boundaries, land use, vegetation type/density, and soil moisture play a dominant role in determining the short-term evolution of weather conditions (Pielke 
et al. 1991; Xian and Pielke 1991; McCumber and Pielke 1981). Hence, guidance from current generation global and regional models is of limited value for these forecasting problems.

The implementation of mesoscale modeling systems locally at KSC/CCAS is ultimately intended to provide accurate forecasts of specific thunderstormrelated phenomena such as lightning, precipitation, and high winds. These forecasts are important for reducing downtime due to false weather advisories and alerts and minimizing the impact on personnel and equipment due to hazardous weather events occurring without warning. Improved forecast reliability may also permit safe relaxation of weather-related launch commit criteria for manned and unmanned space launches and flight rules for shuttle landings.

To meet the forecasting needs at $\mathrm{KSC} / \mathrm{CCAS}$, NASA funded Mesoscale Environmental Simulations and Operations (MESO), Inc. to develop a version of the Mesoscale Atmospheric Simulation System (MASS) configured specifically for short-range forecasting in the vicinity of KSC/CCAS. In this configuration, the model is run at a horizontal resolution of $11 \mathrm{~km}$ with physical parameterizations for precipitation, radiation, and surface hydrology physics that are designed to predict convection induced by local variations in surface heat and moisture fluxes, and cloud shading.

MASS is one of several mesoscale modeling systems that has been used for both basic and applied research including model development (e.g., Kaplan et al. 1982; Uccellini et al. 1987) and detailed case studies (e.g., Kaplan et al. 1985; Zack and Kaplan 1987; Manobianco et al. 1991; Manobianco et al. 1994) for more than 10 years. Other mesoscale models that have been used for numerous phenomenological and modeling studies include the Pennsylvania State University/National Center for Atmospheric Research (PSU/NCAR) mesoscale model (e.g., Kuo et al. 1992; Doyle and Warner 1993a), the Regional Atmospheric Modeling System (RAMS) (e.g., Pielke 1974; Cram et al. 1992), and the Naval Research Laboratory's limited area model (e.g., Holt et al. 1990; Chang et al. 1993).

State-of-the-art mesoscale modeling systems typically contain detailed physical parameterizations and are run at very high horizontal and vertical resolutions. As a result, the models require large memory and processing capabilities, and until recently, could only be run on the fastest supercomputing platforms such as the CRAY-YMP. However, the development of computer workstations during the past five years with sufficient memory and processing speed has permitted mesoscale models to generate real-time forecasts at a fraction of the financial cost that would be required to run these models on mainframe supercomputers (Buzbee 1993).

The version of the MASS model developed to support operational weather forecasting at $\mathrm{KSC} / \mathrm{CCAS}$ is designed to run in real time on high performance workstations. There are other applications where mesoscale model forecasts are performed in real time on mainframe or workstation-class computers. For example, the PSU/NCAR mesoscale model is run routinely on an IBM 3090 to support research, teaching, and public service in the Department of Meteorology at PSU (Warner and Seaman 1990). The RAMS model has also been run in real time on a Stardent 3040 workstation at the Colorado State University (CSU) to generate mesoscale forecasts during the 1991-1992 winter season over the Colorado Rocky Mountains (Cotton et al. 1994). In addition, the Forecast Systems Laboratory (FSL) runs RAMS on an IBM RISC 6000/Model 580 workstation to produce real-time forecasts that are displayed at FSL's in-house daily weather briefings (Snook et al. 1995). Table 1 highlights the basic attributes of the real-time mesoscale modeling systems at PSU, CSU, and FSL.

At KSC/CCAS, RAMS is run without precipitation or cloud physics in real time on an IBM RISC 6000/Model 550 workstation as part of the Emergency Response Dose Assessment System (ERDAS). In ERDAS, the resulting wind fields from RAMS are used to drive dispersion models that could provide emergency response guidance to operations at $\mathrm{KSC} / \mathrm{CCAS}$ in case of a hazardous material release or an aborted vehicle launch (Tremback et al. 1994). ERDAS is currently being evaluated for operations at KSC/CCAS. Additionally, a parallelized version of RAMS with precipitation and cloud physics is being developed by the ASTER Division of Mission Research Corporation to run on a cluster of workstations. The Parallelized RAMS Operational Weather Simulation System (PROWESS) is designed specifically for localized and sea-breeze thunderstorm forecasting at KSC/CCAS (Lyons et al. 1994).

The MASS and RAMS models are currently run on workstations located in the Applied Meteorology Unit (AMU) at KSC/CCAS. The AMU was formed in September 1991 by a triagency Memorandum of Understanding among NASA, the USAF, and the Na- 
TABLE I. Basic attributes of selected real-time mesoscale modeling systems. See text for discussion and references listed for additional information.

\begin{tabular}{|c|c|c|c|}
\hline $\begin{array}{c}\text { Model } \\
\text { (reference) }\end{array}$ & $\begin{array}{c}\text { PSU/NCAR } \\
\text { (Warner and Seaman 1990) }\end{array}$ & $\begin{array}{c}\text { RAMS/CSU } \\
\text { (Cotton et al. 1994) }\end{array}$ & $\begin{array}{c}\text { RAMS/FSL } \\
\text { (Snook et al. 1995) }\end{array}$ \\
\hline $\begin{array}{l}\text { Horizontal grid } \\
\text { dimensions } \\
\text { (grid resolution) }\end{array}$ & $\begin{array}{l}41 \times 41(90 \mathrm{~km}) \\
43 \times 43(30 \mathrm{~km})\end{array}$ & $\begin{array}{l}36 \times 28(100 \mathrm{~km}) \\
34 \times 30(25 \mathrm{~km})\end{array}$ & $61 \times 61(10 \mathrm{~km})$ \\
\hline $\begin{array}{l}\text { Number of } \\
\text { vertical levels }\end{array}$ & 15 & 25 & 25 \\
\hline $\begin{array}{l}\text { Boundary-layer } \\
\text { physics }\end{array}$ & $\begin{array}{c}\text { Blackadar } \\
\text { (Zhang and Anthes 1982) }\end{array}$ & $\begin{array}{c}\text { Smagorinsky deformation } \\
\text { K closure } \\
\text { (Smagorinsky 1963) }\end{array}$ & $\begin{array}{l}\text { Smagorinsky deformation } \\
\text { K closure } \\
\text { (Smagorinsky 196.3) }\end{array}$ \\
\hline $\begin{array}{l}\text { Grid-scale } \\
\text { precipitation } \\
\text { physics }\end{array}$ & $\begin{array}{l}\text { Condense water vapor in } \\
\text { excess of supersaturation } \\
\text { to form precipitation }\end{array}$ & $\begin{array}{l}\text { Condense water vapor in } \\
\text { excess of supersaturation; } \\
\text { dump a portion as precipitation } \\
\text { (Flatau et al. 1989) }\end{array}$ & $\begin{array}{c}\text { Condense water vapor in } \\
\text { excess of supersaturation } \\
\text { to cloud water } \\
\text { No precipitation }\end{array}$ \\
\hline $\begin{array}{l}\text { Subgrid-scale } \\
\text { precipitation physics } \\
\text { (cumulus } \\
\text { parameterization) }\end{array}$ & $\begin{array}{c}\text { Kuo type } \\
\text { (Kuo 1974; Anthes 1977) }\end{array}$ & None & None \\
\hline Radiation physics & $\begin{array}{l}\text { Shortwave and longwave } \\
\text { radiative surface fluxes adjusted } \\
\text { based on clouds specified } \\
\text { as a function of predicted } \\
\text { relative humidity }\end{array}$ & $\begin{array}{l}\text { Radiative effects of water vapor, } \\
\text { ozone, and carbon dioxide } \\
\text { (Mahrer and Pielke 1977) }\end{array}$ & $\begin{array}{l}\text { Radiative effects of water } \\
\text { vapor and clouds } \\
\text { (Mahrer and Pielke 1977; } \\
\text { Thompson 1993) }\end{array}$ \\
\hline
\end{tabular}

tional Weather Service (NWS). The AMU's mission is to evaluate and transfer new technology into the real-time weather support environment for the USAF Range Weather Operations (RWO) at CCAS and the National Oceanic and Atmospheric Administration's (NOAA's) Spaceflight Meteorology Group (SMG) at the Johnson Space Center. The RWO and SMG are the two agencies that provide direct weather support to NASA. As part of a coordinated technology transition plan for mesoscale numerical modeling, the AMU is currently evaluating MASS and ERDAS, and will be evaluating PROWESS. Based on the results of the evaluations, the AMU will recommend and/or develop modifications to these systems to make them suitable for operational use and work with the Eastern Range to generate documentation and training necessary for certified Range systems.

The objective of this paper is to describe the general capabilities and operational utility of the version of MASS, which has been designed specifically for short-range forecasting at KSC/CCAS. Section 2 pro- vides an overview of the system and discusses the statistical forecast component of MASS that is unique for this application. Section 3 illustrates the performance of MASS for a specific case. Section 4 highlights aspects of a system evaluation including the MASS model performance over many cases in predicting mesoscale patterns of precipitation. Section 5 concludes with a summary and a discussion of some outstanding issues and problems relating to local mesoscale modeling at $\mathrm{KSC} / \mathrm{CCAS}$.

\section{System overview}

The MASS forecast system is composed of three main components: 1) an initialization module, 2) a dynamical model, and 3) a set of statistical models that generate probability forecasts of specific weather events from dynamical model output and observations. The initialization module and dynamical model are summarized in Tables 2 and 3, respectively. 
TABl.H 2. MASS initialization module attributes.

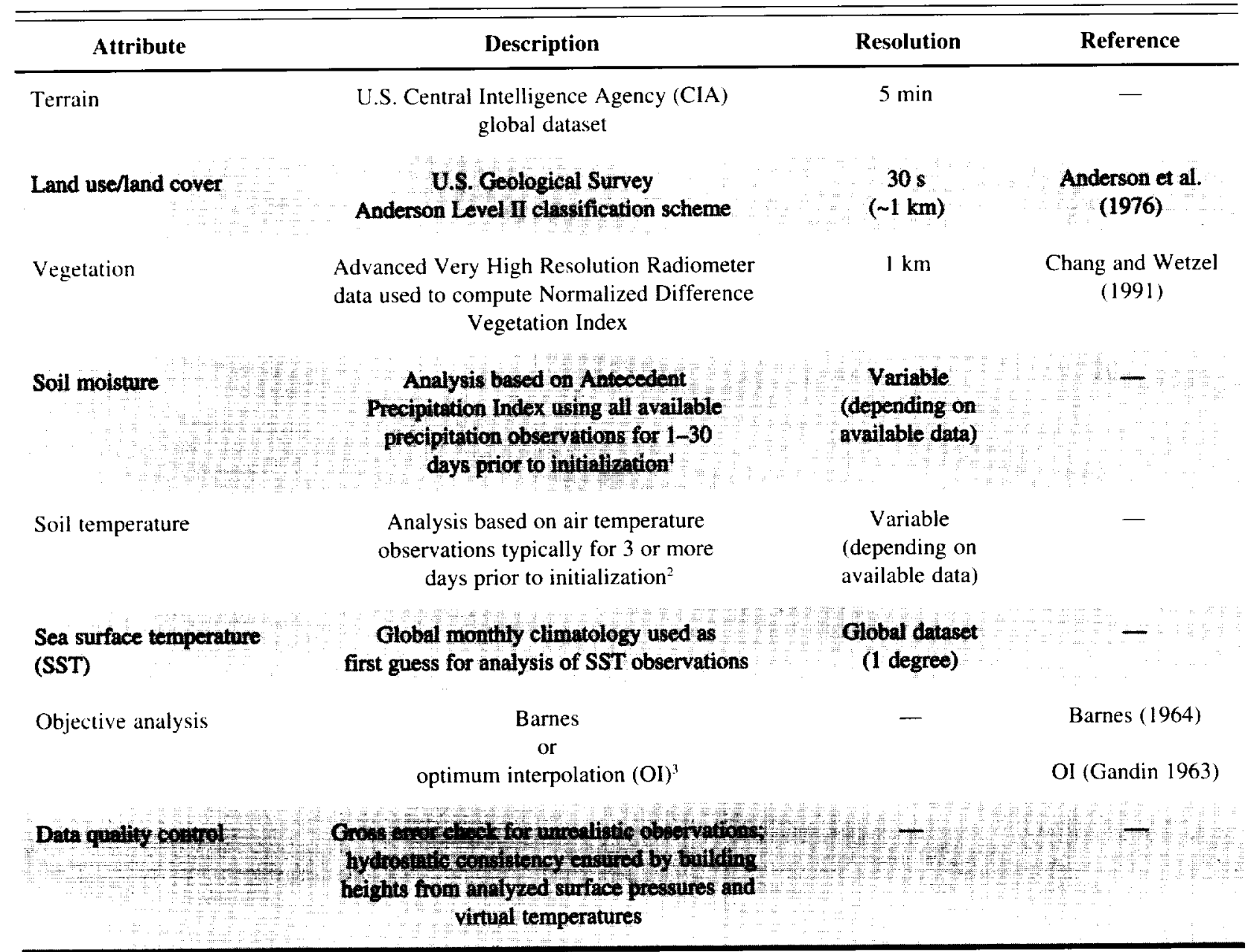

1 Presently initialized to a constant value of 0.2 .

2 Presently initialized to surface temperature.

${ }^{3}$ Presently used only for sea surface temperature analysis.

\section{a. Initialization module}

The initialization module, or data preprocessor, performs surface parameter specification and surface and atmospheric variable initialization. The surface parameter routines determine the model horizontal grid structure and specify nonprognostic parameters such as terrain height, land-water classification, land use, and fraction of the surface covered by vegetation. The data sources and resolution used to initialize these parameters are given in Table 2 .

There are a number of in situ and remotely sensed data sources that are presently used to initialize the MASS model. The gridded data from the National Meteorological Center's (NMC) Nested Grid Model (NGM) $\mathrm{C}$ grid provides first-guess fields for a Barnes (1964) objective analysis of rawinsonde data. The raw
NGM C-grid data available at $\mathrm{KSC} / \mathrm{CCAS}$ have a horizontal spacing of $1.25^{\circ}$ latitude $\times 2.5^{\circ}$ longitude on 10 mandatory pressure levels from 1000 to $100 \mathrm{mb}$. MASS incorporates surface data including measurements of temperature, winds, moisture, and clouds from land-based stations, ships, and buoys; and wind, temperature, and dewpoint temperature from the mesoscale network of instrumented towers surrounding $\mathrm{KSC} / \mathrm{CCAS}$. The surface data are objectively analyzed to the model grid using a two-pass Barnes (1964) objective analysis scheme. The locations of available rawinsonde, surface, buoy, ship, and $\mathrm{KSC} / \mathrm{CCAS}$ tower observations at initialization time for a typical model run are shown in Fig. 1.

The three-dimensional initial moisture analyses are enhanced by creating synthetic relative humidity 
TABLE 3. MASS model attributes.

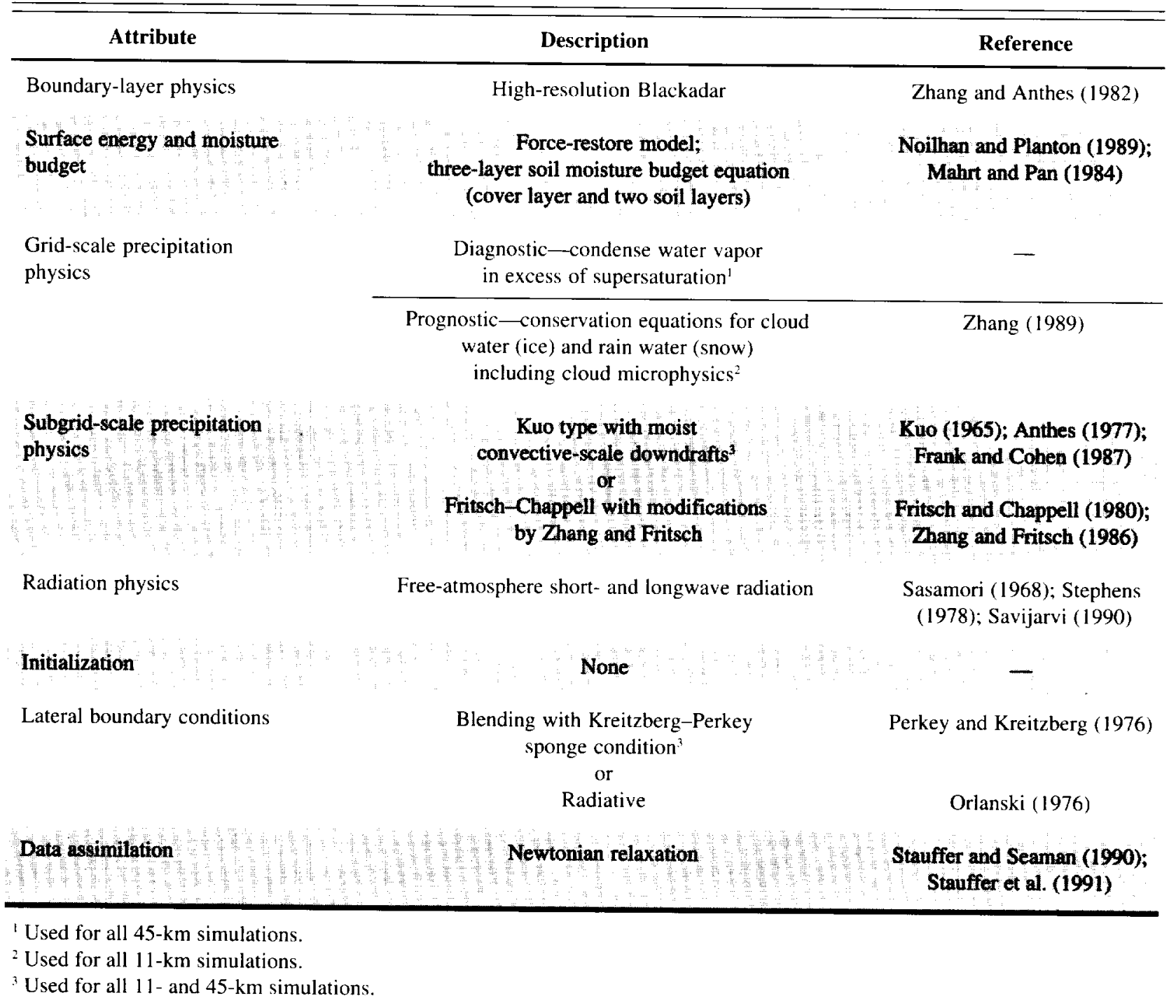

(RH) fields from a combination of manually digitized radar (MDR) data, visual surface-based cloud observations, and infrared satellite data. The scheme consists of three basic steps and is described in MESO (1993) and Young and Zack (1994).

In the first step, synthetic RH values are derived from surface observations of cloud and current weather as well as pilot reports of clouds. To obtain RH values from surface cloud and weather observations, statistical equations that relate visual observations of clouds and weather to vertical relative humidity profiles were developed from a database of collocated surface and rawinsonde observations. An RH-height relationship with a vertical resolution of $25 \mathrm{mb}$ was derived for each cloud/weather category (e.g., middle overcast with precipitation) using the observed cloud- base heights as predictors. An objective analysis scheme is used to blend these synthetic RH values with RH measurements using a first-guess gridpoint field of RH.

The second step uses IR radiance data to estimate the fractional cloud coverage and cloud-top height distribution in each model grid cell. Cloud base is estimated from the cloud observations at the nearest surface station. Model grid points are then moistened or dried depending on the fractional cloud coverage through the use of the same RH-cloud fraction relationship used to diagnose clouds in the dynamical model.

In the third step, grid cells with precipitation are identified using MDR reports of echo intensity and areal coverage of precipitation and the location of convective towers determined from the IR satellite data following Adler and Negri (1988). The grid cells 

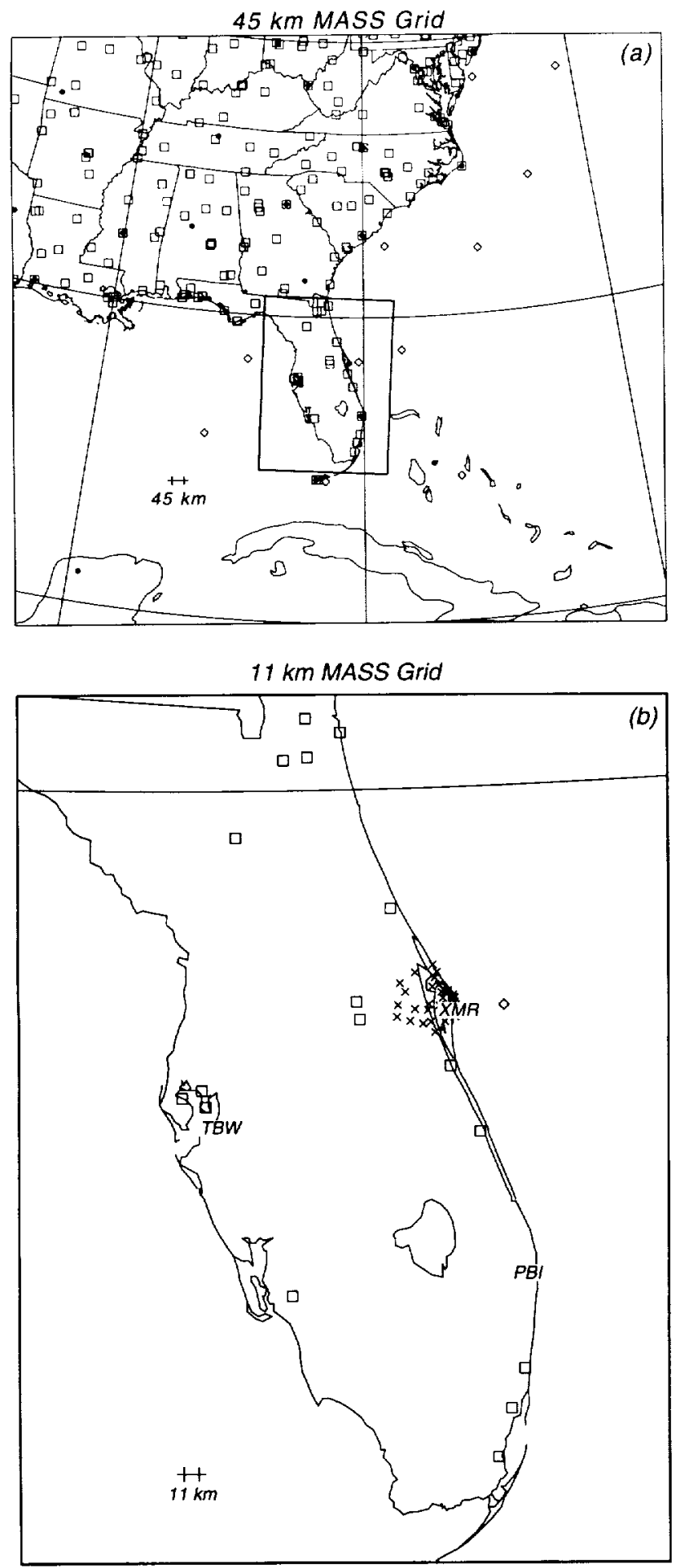

Fig. 1. Depiction of the geographical domain covered by the horizontal grid matrices used in (a) the $45-\mathrm{km}$ (coarse mesh) and (b) the 11-km (fine mesh) mesoscale simulations. Panel (b) contains an expanded view of the $11 \mathrm{~km}$ domain given by the inner rectangle in panel (a). Representative 45 - and $11-\mathrm{km}$ grid intervals are labeled in each panel. The locations of available data for typical coarse- and fine-grid model runs are shown as solid dots for rawinsondes, open squares for surface stations, open diamonds for ships and buoys, and ' $\mathrm{X}$ 's for KSC/CCAS towers. The with diagnosed precipitation are brought to near saturation from the cloud top to the surface of the earth.

\section{b. Dynamical forecast model}

The dynamical forecast model used in this system is version 5.6 of the MASS model. It is a hydrostatic three-dimensional primitive equation model that is a descendent of version 2.0 described by Kaplan et al. (1982). The attributes of the MASS model are summarized in Table 3. A detailed description of version 5.6 and specific enhancements to MASS developed for application to forecasting at $\mathrm{KSC} / \mathrm{CCAS}$ are provided elsewhere (MESO 1993). MASS 6.0, which will include a full nonhydrostatic equation set, a more detailed multiphase water microphysics parameterization, and a turbulent kinetic energy-based boundary layer parameterization, is scheduled to be completed during the second half of 1996.

The KSC/CCAS real-time version of the model is currently run with a coarse-grid spacing of $45 \mathrm{~km}$ $(55 \times 50$ points) covering the southeastern United States and a fine-grid spacing of $11 \mathrm{~km}(45 \times 60$ points) covering the Florida peninsula, the eastern Gulf of Mexico, and western Atlantic Ocean. There may be some concern about executing a hydrostatic version of MASS with a grid spacing as fine as 11 $\mathrm{km}$. However, experiments with the nonhydrostatic version of the PSU/NCAR model indicate that results from nonhydrostatic and hydrostatic simulations are virtually identical in most situations for grid spacings above $10 \mathrm{~km}$ (e.g., Dudhia 1993; Doyle and Warner 1993b). The extent of the 45- and 11-km domains is shown in Fig. 1. The vertical spacing of the model's 20 sigma layers used for both coarse- and fine-grid runs varies from $\sim 20 \mathrm{~m}$ at the lower boundary (i.e., the surface) to $\sim 2 \mathrm{~km}$ at the upper boundary (i.e., $100 \mathrm{mb}$ ).

The MASS data preprocessor and model have been running twice daily on a four-processor Stardent 3000 workstation since January 1994. Section 4 provides additional details concerning the model's performance on the Stardent 3000 and other computing platforms. The attributes and simulation schedule for the real-time MASS configuration are summarized in Fig. 2. The daily model forecast and data assimilation schedule consists of two 24-h coarse-grid and two 12-h fine-grid runs per day. The 24-h coarse-grid run designated $\mathrm{COO}$ is initialized with 0000 UTC data

rawinsonde sites at West Palm Beach (PBI), Tampa Bay (TBW), and Cape Canaveral (XMR) used for verification are indicated by the three letter station identifiers in panel (b). 
and assimilates hourly gridded analyses of surface and MDR data from 0000 to 0400 UTC. The hourly surface analyses used for data assimilation via Newtonian relaxation or nudging (Table 3 ) are derived from all available synoptic surface, buoy, ship, and $\mathrm{KSC} / \mathrm{CCAS}$ tower observations at the locations shown in Fig. 1. The MDR data are transmitted on NMC's Domestic Data Service at 35 minutes past each hour. MASS does not presently assimilate any asynoptic data available over the coarse- or fine-grid domains shown in Fig. 1. The nudging coefficient is set to 0.0003 for both surface and MDR analysis nudging. Finally, the NGM forecasts generated from 0000 UTC data are used to derive lateral boundary conditions (BC) for the $\mathrm{C} 00$ run. The $\mathrm{BC}$ are linearly interpolated in time from the NGM forecast data at $0,6,12,18$, and $24 \mathrm{~h}$.

The 12-h fine-grid run, designated F12, is initialized with 1200 UTC data and assimilates 1300 UTC surface and MDR data. The $12-\mathrm{h}$ forecast from $\mathrm{C} 00$ (valid at 1200 UTC) provides the first-guess fields for the objective analysis of 1200 UTC data used for F12 initialization. Additionally, the 12-24-h forecast fields from $\mathrm{C} 00$ are used to specify lateral $\mathrm{BC}$ for the F12 run. For each time step of the F12 run, the BC are linearly interpolated from the $\mathrm{COO}$ output at 1-h intervals. The cycle is repeated using 1200 UTC data to initialize the 24-h coarse-grid run designated C12 and 0000 UTC data to initialize the 12-h finegrid run designated F00.

The main goal of the daily forecast-assimilation cycle is to initialize the fine-grid runs as early as possible with current upper-air data. Therefore, the F00 and F12 runs are started approximately $1 \mathrm{~h}$ after the synoptic data times of 0000 and 1200 UTC, respectively (Fig. 2). Since the $\mathrm{C} 00(\mathrm{C} 12)$ forecast is designed primarily to provide first-guess fields and lateral $\mathrm{BC}$ for the F12 (F00) forecast, it is started well after the synoptic data time at 0715 UTC (1915 UTC). As a result, the 0000 UTC (1200 UTC) NGM initial analyses and forecasts can be used for the $\mathrm{COO}(\mathrm{C} 12)$ run since all of the 0000 UTC (1200 UTC) NGM gridded data are usually received by 0300 UTC (1500 UTC) at CCAS. The earliest time that forecast products are available and the time that all forecast products are available from coarse- and fine-grid runs are given in Fig. 2. It is important to point out these times are for MASS model forecasts executed on an IBM RISC 6000/Model 390 rather than the Stardent 3000. The same daily forecast and assimilation cycle shown in Fig. 2 has been running on the AMU's Model 390

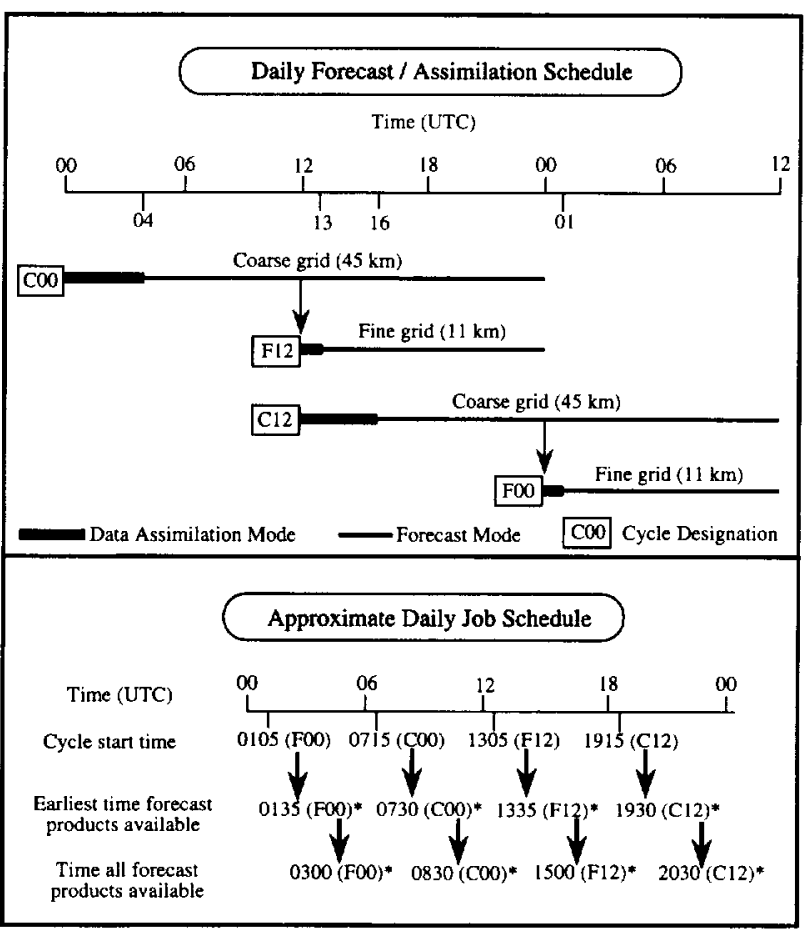

*Note product availability times shown are for MASS model runs on an IBM RISC 6000 ? Model 390 rather than the Stardent 3000 discussed in the text.

FIG. 2. Operational real-time daily forecast, data assimilation, and job schedule at $\mathrm{KSC} / \mathrm{CCAS}$.

since March 1995. The Model 390 executes MASS approximately three times faster than the four-processor Stardent 3000.

\section{c. Statistical model}

The computational constraints and the unavailability of high-resolution initialization data prohibit the execution of MASS with sufficient resolution and detailed physics to predict precise occurrences of specific weather phenomena such as thunderstorms and lightning at $\mathrm{KSC} / \mathrm{CCAS}$. As a result, a statistical model was incorporated into the MASS prediction system. The basic concept was to combine model and observational data in a way that would permit the generation of hourly updates of the probability of specific weather phenomena at KSC/CCAS during specified time windows. The expectation was that model-generated variables would have more predictive skill in the longer-lead-time forecasts (i.e., early in the day) and that the "latest" values of observationbased variables would provide most of the information for the short lead-time (a few hours before the target time window) forecasts. The system was intended to provide a mechanism to transition smoothly from predictions based more heavily on model-gen- 
erated variables to those based on observational data as the time of the forecast target window approached. This approach is similar in concept to the Model Output Statistics (MOS) schemes used by NMC to generate forecasts of local variables from regional or global model output.

The statistical model consists of a set of linear discriminant functions (LDFs; Fischer 1938). In the prototype version of the system, LDFs were developed for four consecutive 2-h forecast time windows covering the period from 1500 to 2300 UTC and four predictand events: 1) a lightning stroke detected within $10 \mathrm{~km}$ of the KSC/CCAS weather observation site (TTS); 2) a report of thunder heard at TTS; 3 ) a report of rain at the TTS site in either regular or special observations; and 4) a report of a wind gust of $15 \mathrm{~m} \mathrm{~s}^{-1}$ or higher at any of the KSC/CCAS mesonet towers within $10 \mathrm{~km}$ of TTS. This statistical model can be used to generate an estimate of the probability of the occurrence of each event within any of the forecast windows.

The statistical model was designed to use both observation-based data and model-generated data simultaneously, generate a new forecast each hour, and generate forecasts beginning at 0000 UTC each day for the afternoon period (1500-2300 UTC) of that day. A separate LDF was constructed for each forecast-generation hour for each of the predictands. All of the selected variables (observation based or model generated) that were normally available by the start of a particular hour were used as candidate predictors for that hour. Thus, variables based solely on observational data could be included in the prediction equation for any hour after the time that they were reported. For example, a variable based on the MDR data reported at 2035 UTC could be used $25 \mathrm{~min}$ after the reporting time as a predictor in the 2100 UTC forecast equation. In the case of variables computed from model-generated data, the variables were eligible for consideration as a LDF predictor for any hour after the time that the model simulation normally terminated. Thus, if a scheduled model simulation normally began execution at 0230 UTC and finished at 0630 UTC, then any variable computed from the output of that simulation was considered as a candidate only for the LDFs at or after 0700 UTC. A list of the observation-based and model-generated variables considered as candidate predictors is given in Zack et al. (1993). The predictors for each hour's LDF were selected from the pool of potential predictors by evaluating the discriminating power of all combina- tions of three variables and selecting the set of three that yielded that highest ability to discriminate between the occurrence and nonoccurrence of each event. The predictor set for each hour was limited to three to avoid overfitting of the data in the limited size developmental sample.

A preliminary set of LDFs were derived from a sample of 58 warm season cases from the summer of 1992. The 58 cases were a subset of a sample of 102 cases for which real-time MASS simulations were generated on a daily basis between mid-July and October of 1992. The sample size for the derivation of the statistical equations was set to 58 because that was the number of cases for which a complete set of observational and simulated data needed to define the predictors and predictands was available. The dominant reason that cases in the 102-case database of realtime MASS simulations had to be excluded from the statistical sample was the inability to retrieve data from $\mathrm{KSC} / \mathrm{CCAS}$ sensors because of communications difficulties. As a result, the sample size was undesirably small. The small sample size prevented the evaluation of the statistical equations on an independent dataset and therefore any results from the statistical component of this system must be viewed as preliminary.

The observational data and forecast data from the 45- and $11-\mathrm{km}$ simulations were used for the derivation of all of the statistical equations. Given the small sample size, there was no attempt to isolate the relative impact of any data subset (e.g., only $11-\mathrm{km}$ forecasts and observations) on the discriminating power of the LDFs. The AMU has compiled simulated and observational data from daily real-time MASS runs during the warm seasons of 1994 and 1995. This database will permit the statistical equations to be derived from a larger sample size and will also provide an opportunity to evaluate the statistical models on an independent data sample. This sample will also provide an opportunity to assess the relative value of the $45-$ and $11-\mathrm{km}$ simulations in providing predictors with significant discriminating power for the selected predictand events.

An example of the potential impact of the dynamical-statistical modeling combination on the objective forecasting of thunderstorm events at KSC/CCAS is illustrated in Fig. 3. This chart illustrates the probability of correctly forecasting an event of thunder with rain at 1200 UTC in the 2-h period from 2100 to 2300 UTC during the warm season with four different methods. The probability estimates are based upon the use of decision rules from the LDFs derived 
from the preliminary sample of 58 warm season cases from 1992. The first method is simply an application of the climatological probability based solely upon the day of the year. The analysis of the 58-case sample indicates that this will yield a correct forecast of the event about $68 \%$ of the time. A more sophisticated form of climatological forecast is to combine the climatology with information from the morning XMR sounding. The probability of making a correct forecast with this method is estimated to be $73 \%$. The third method is to use the statistical model with only observational data. This approach would be expected to generate a correct forecast slightly under $80 \%$ of the time. The most comprehensive method is to use the statistical model with both observation-based and mesoscale-model-generated variables. The data from the limited 58-case sample indicate that this will give the correct forecast slightly over $83 \%$ of the time. The same performance relationship among these forecasting techniques was found to exist for the other time periods and events considered in the developmental sample.

\section{Case example}

The 19 February 1992 case provides an illustration of the improved forecast guidance that could potentially be gained by executing a mesoscale model over the Florida peninsula. This case was important from an operational perspective because the USAF scrubbed the second launch attempt of a Delta II rocket from Launch Complex 17B at CCAS (see image on cover) due to thick clouds ( $>4500 \mathrm{ft}$ thick) and disturbed weather (i.e., any meteorological phenomena producing moderate or greater precipitation). The adverse weather was related to an area of thunderstorms that developed to the southwest of KSC/CCAS during the afternoon hours in advance of a dissipating frontal band. The forecasters at CCAS set the overall probability of weather constraint violation for the operation to $30 \%$ just 90 min prior (2029 UTC) to the beginning of the launch window. The initial development of this isolated convection was not predicted by the NGM but was simulated by the MASS model. The performance of MASS for this case was not spectacular, but it demonstrates the skill that the model can exhibit when mesoscale circulations are an important contributor to the initiation and evolution of convective storms.

At 1200 UTC 19 February 1992, a deep cyclone was located over the eastern Great Lakes. A frontal band extended southward through coastal South Carolina, across the northern portion of the Florida peninsula and into the Gulf of Mexico. The band is evident in the manually digitized radar (MDR) depictions shown in Fig. 4. The band of echoes over northern Florida was a result of low to middle clouds and light precipitation associated with the frontal zone. This band moved very slowly southward and gradually weakened during the day. The weather to the south of the band was generally clear.

The development of the small area of thunderstorm activity to the southwest of KSC/CCAS was apparently forced by two mesoscale circulations that developed over the Florida peninsula during the daylight hours. One circulation was associated with a cloud boundary on the southern edge of the southwestnortheast cloud band over northern Florida. The atmospheric boundary layer was heated significantly in the region of nearly clear skies to the south of the cloud band while the low-level air within the cloud band remained relatively cool. This can be seen in Fig. 5 by noting the increase in the surface temperature gradient from northern Florida to central Florida between 1500 and 2100 UTC. The observational data in Fig. 5 suggest that this north-to-south differential heating had a significant impact on the low-level pressure and wind fields.

A nested MASS simulation was initialized at 1200 UTC 19 February 1992. This simulation was executed over the $45-\mathrm{km}$ coarse-mesh and $11-\mathrm{km}$ finemesh domains shown in Fig. 1. The model was in the

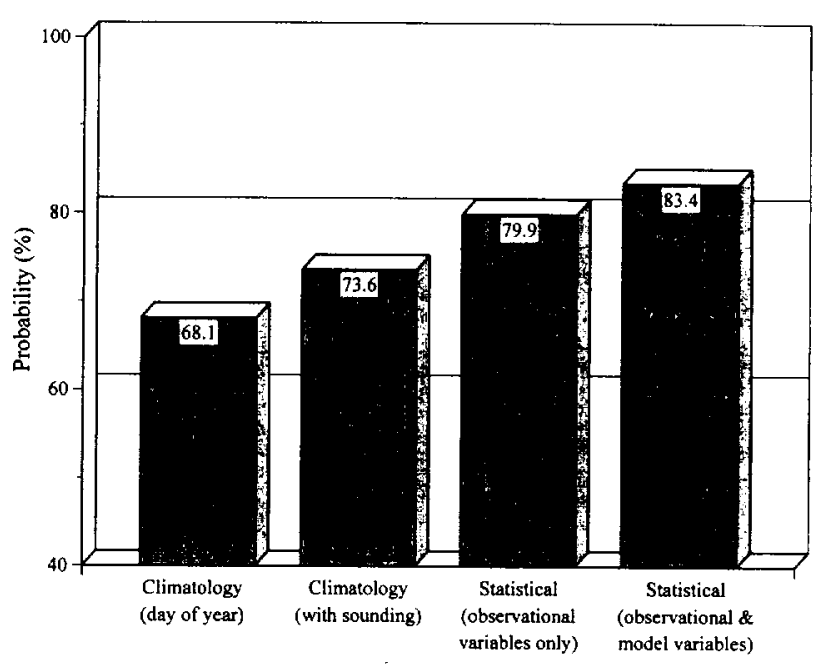

FIG. 3. The probability of correctly predicting a thunderstorm with rain event for the 2100-2300 UTC at 1200 UTC using four different forecasting techniques. The probabilities are based upon the utilization of linear discriminant functions derived from a 58-case sample for the summer of 1992 . 


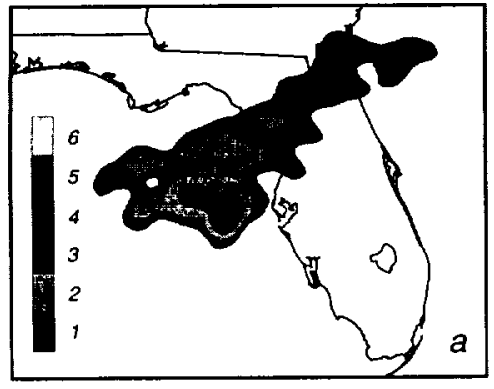

1535 UTC

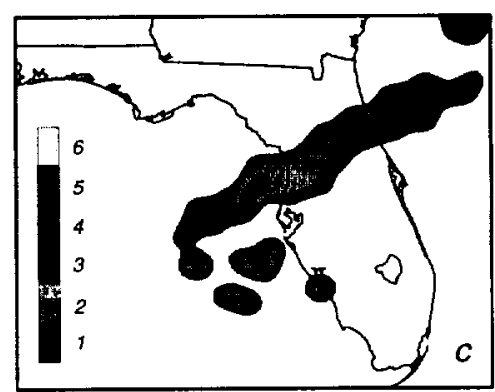

2135 UTC

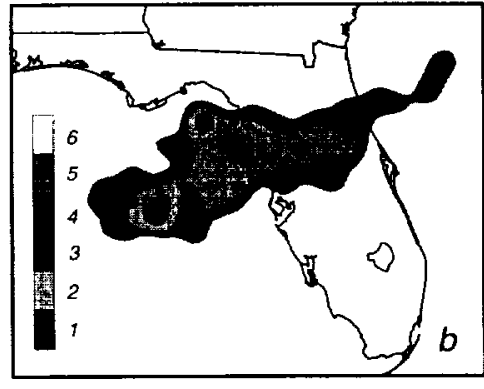

1835 UTC

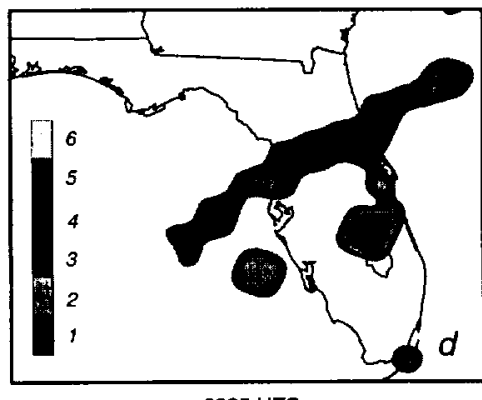

2235 UTC
FiG. 4. Manually digitized radar depiction for 19 February 1992 at (a) 1535 UTC, (b) 1835 UTC, (c) 2135 UTC, and (d) 2235 UTC. Echo intensities (VIP levels) $1-6$ are shaded gray according to the legend in each panel.

operational configuration and used only data that are routinely available to the operational system. Soil moisture can be initialized in MASS from the observed history of precipitation. However, as in the current operational runs at KSC/CCAS, the soil moisture in this simulation was set to a single climatologically representative value throughout the land areas in the model domain. Hence, none of the circulation features in the simulation can be attributed to variations in initial soil moisture.

Evidence of the circulation associated with the cloud boundary can be seen clearly in the model output data in Fig. 6. The predicted shortwave transmissivity for 1800 UTC (Fig. 6a) illustrates the simulated position of the cloud boundary. At this time, the model has already created a substantial north-to-south surface thermal gradient (Fig. 6b) in the vicinity of the cloud boundary, and there is an incipient mesoscale low-pressure center located over central Florida on the southern edge of the thermal gradient. The model output fields for 2200 UTC (Figs. 6c,d) indicate that the cloud boundary feature is well developed. There is pronounced diffluence in the low-level wind field just to the north of the mesolow along the axis of a surface pressure ridge in the cloudy region. On the northern side of the ridge line, the simulated winds are from the southwest, while to the south of this ridge the winds have a weaker southerly component and a stronger westerly component that results in significant confluence farther to the south in the vicinity of the simulated mesolow. The confluence is even stronger in the observed wind field because the observed winds between the ridge and the mesolow (Fig. 5d) have a stronger northerly component than the simulated winds (Fig. 6c).

The second significant mesoscale circulation was a classic sea breeze. Since the large-scale winds on this day were from the west, it would be expected that the strongest sea-breeze convergence would occur along the east coast of the peninsula where the sea breeze opposes the background large-scale flow. The observations at 2200 UTC (Fig. 5d) suggest that a sea-breeze circulation was present along the southeast coast of Florida from Miami northward to Vero Beach. However, to the north of Vero Beach, the sea breeze was suppressed by the lack of boundary-layer heating due to cloud cover. The simulated 2200 UTC wind field shows an onshore sea-breeze flow present along the southeast coast of the peninsula up to the Vero Beach area with no onshore flow to the north of the KSC/CCAS area as observed (Fig. 5c).

The small area of new thunderstorm activity that was of interest to the KSC/CCAS operational personnel developed between the 2135 and 2235 UTC radar summaries (note Figs. $4 \mathrm{c}$,d) near the intersection of the sea-breeze convergence line moving westward from the east coast and the cloud boundary convergence line moving southward from the cloud boundary over north central Florida. The observed position of these two convergence zones can be readily inferred from the surface winds at 2200 UTC (Fig. 5d). The model's moist convective parameterization scheme was triggered at approximately 2200 UTC at several grid points to the southwest of KSC/CCAS and very close to the location where the first radar echoes of the new system were observed. No precipitation was produced by the model anywhere over central Florida to the south of the cloud band before 2200 UTC. The simulated convection moved eastward and crossed the coast just to the south of KSC/CCAS by 0000 UTC 20 February as observed. 


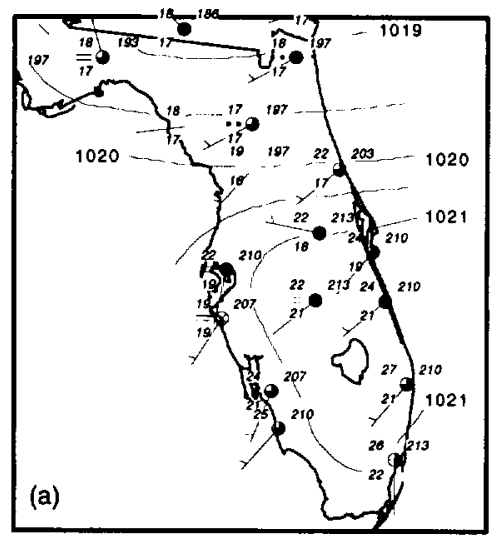

1500 UTC

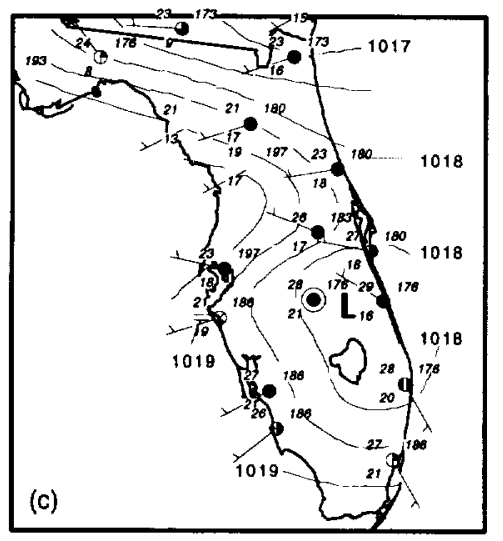

2100 UTC

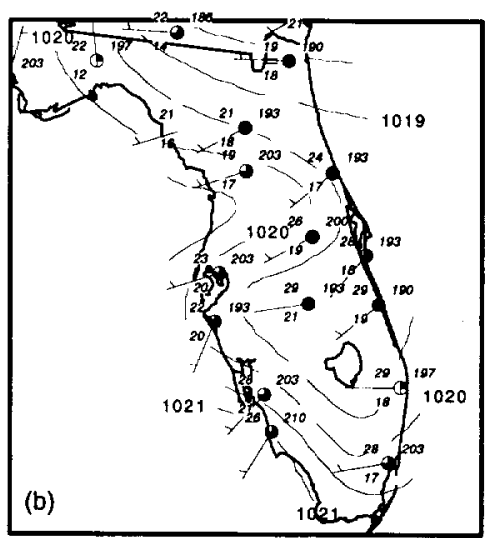

1800 UTC

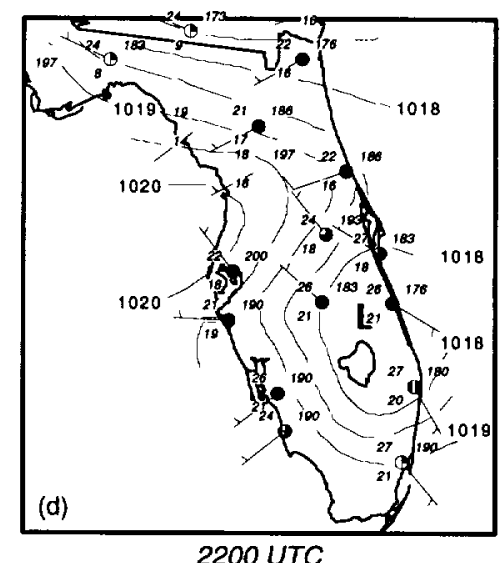

2200 UTC

FlG. 5. Surface weather observation data plotted in standard format at selected sites and a subjective analysis of altimeter setting $(0.5-\mathrm{mb}$ interval) for (a) 1500 UTC, (b) 1800 UTC, (c) 2100 UTC, and (d) 2200 UTC. Only a subset of the stations used to construct the analysis are shown.

The simulated 2-h accumulated precipitation for the period 2200-0000 UTC (Fig. 6e) indicates the area affected by the simulated convective system. The maximum simulated precipitation is $1-2 \mathrm{~mm}$ just to the south of KSC/CCAS, which compares very favorably with an observation of about $1 \mathrm{~mm}$ at Melbourne (shown as $0.76 \mathrm{~mm}$ in Fig. 7c) and approximately $2.5 \mathrm{~mm}$ at a cooperative observational site just to the southwest of Melbourne. The simulated pressure and temperature pattern at 0000 UTC (Fig. 6f) indicates that the system is accompanied by an area of downdraft cooling and a small mesohigh. The timing and magnitude of the observed pressure and temperature perturbations at Melbourne (not shown) were consistent with that of the simulated perturbations.

The 12-h precipitation forecasts produced by the operational NGM model and the 11-km MASS model are compared with observational precipitation data in Fig. 7. At the relatively coarse horizontal grid reso-

lution of $80 \mathrm{~km}$ on the $\mathrm{C}$ grid, the NGM was unable to forecast any of the observed mesoscale variability of the precipitation over the central portion of the Florida peninsula. As a result, it drastically overpredicted the area covered by precipitation. In contrast, the mesoscale model was able to forecast a much more realistic precipitation distribution. It should be noted that current NMC operational analyses and forecasts (e.g., the 29-km version of the eta model), which were not available when this version of the MASS was developed in 1992, employ finer horizontal resolution than the 80-km NGM shown in this comparison.

This example illustrates a case in which the development of moist convection was the result of well-defined mesoscale features that were attributable to differential boundary-layer heating. The modeling system tends to perform well in this type of scenario since 1) many of the factors that control the differential boundary-layer heating (land-water distribution, density of vegetation, soil moisture, and cloud patterns) can be reasonably well mapped for initialization; and 2) the heating patterns themselves, with the possible exception of those due to cloud shading, do not drastically change during the course of the simulation. In contrast, the model does not perform as well in cases in which the evolution of convection is strongly controlled by the feedback from the convection itself (e.g., the development of new convection along thunderstorm outflow boundaries).

\section{System evaluation}

While the previous section highlighted the performance of MASS for a specific case, this section focuses on the evaluation of the system including real-time run statistics, model performance on different computing platforms, and statistical verification of the model over many cases.

\section{a. Real-time MASS run statistics}

The AMU archived output from daily MASS model runs from 15 January 1994 through 15 Octo- 

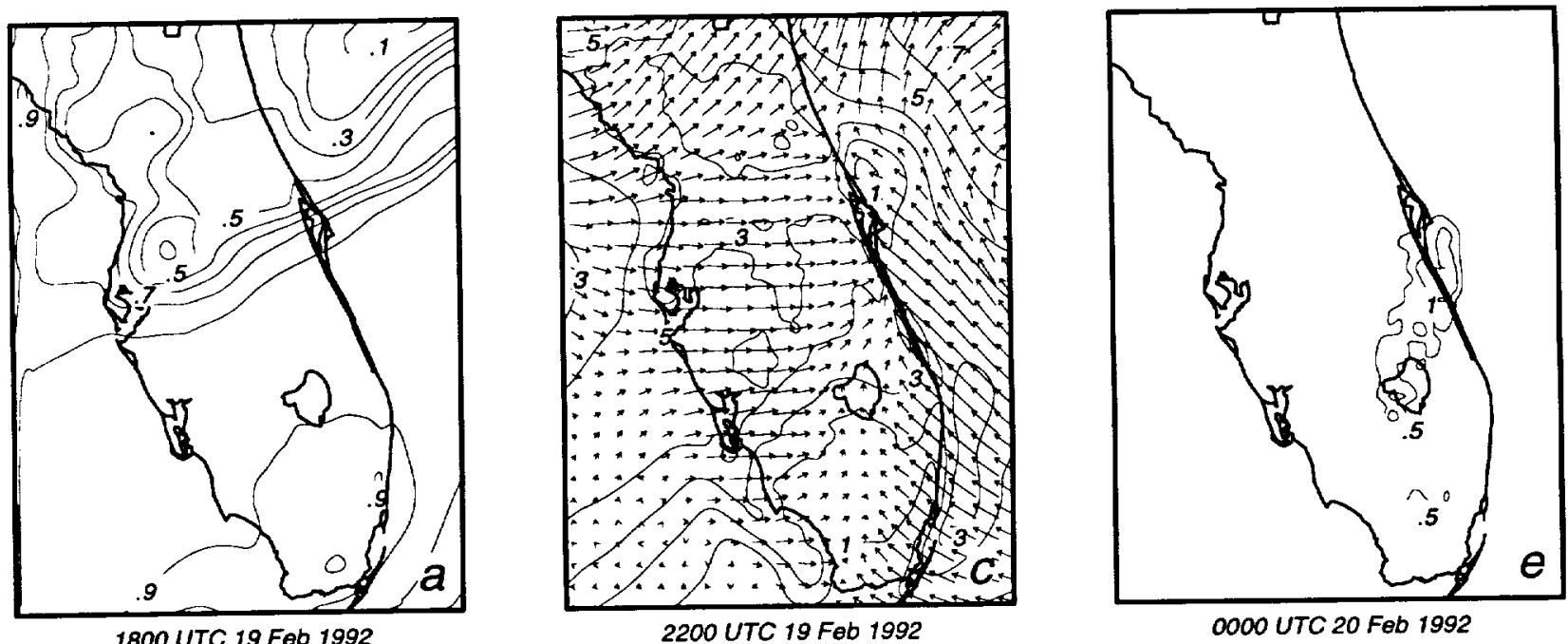

0000 UTC 20 Feb 1992
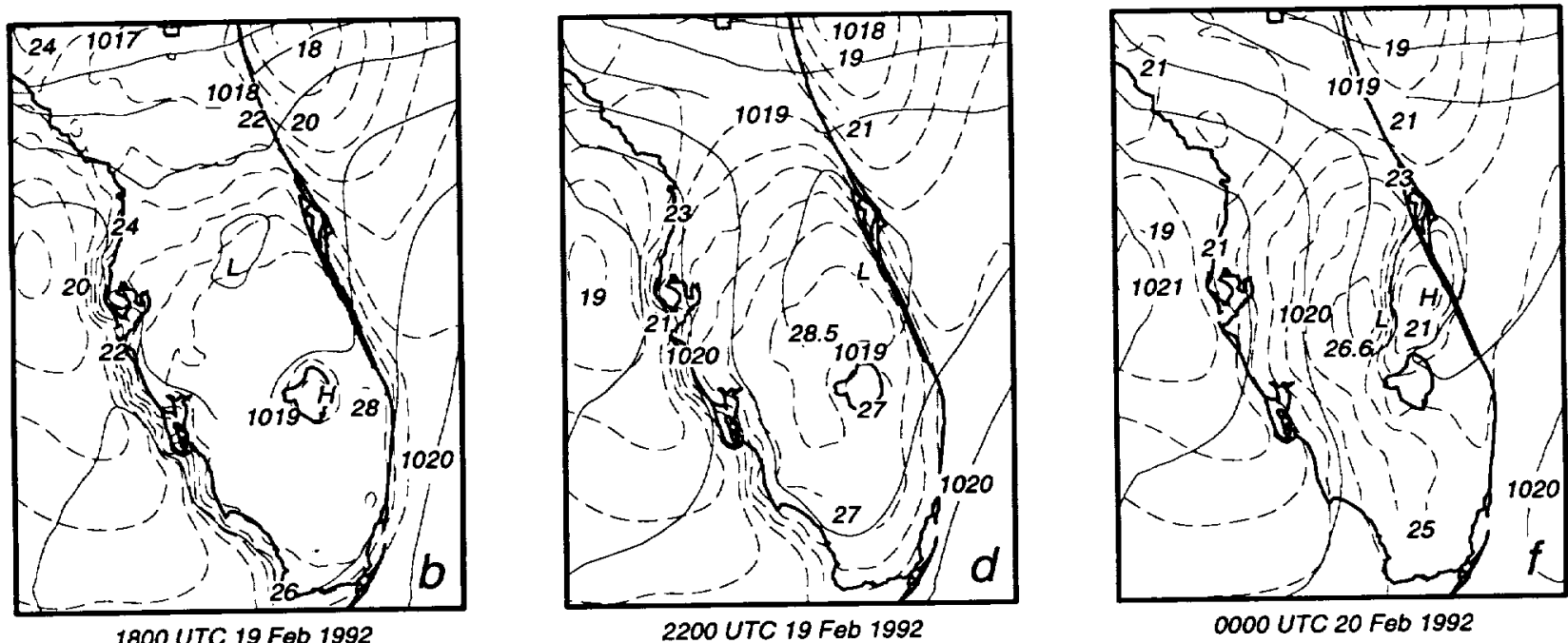

FIG. 6. Simulated fields from an 11-km MASS simulation initialized at 1200 UTC 19 February 1992: (a) 1800 UTC shortwave transmissivity, (b) 1800 UTC 10 -m AGL (above ground level) temperatures (dashed lines; $1{ }^{\circ} \mathrm{C}$ interval) and mean sea level pressure (solid lines; $0.5 \mathrm{mb}$ interval), (c) 2200 UTC 10-m AGL wind vector and isotachs ( $1 \mathrm{~m} \mathrm{~s}^{-1}$ interval), (d) same as (b) except for 2200 UTC, (e) accumulated precipitation $(0.5-\mathrm{mm}$ interval) for the 2 -h period ending at 0000 UTC 20 February, and (f) same as (b) except for 0000 UTC 20 February 1992.

ber 1994 for the purpose of model evaluation. This nine-month archiving period was chosen primarily to assess model performance during all four seasons of 1994. At the end of the archiving period, the number of completed MASS model runs was compared with the number of total possible runs to measure system stability. During this time, no model forecasts were lost due to instabilities generated by the model's physics or dynamics, or problems with the model or data preprocessor software. Furthermore, the majority of $45-\mathrm{km}$ runs that were lost were due to hardware problems or loss of NGM data used as first-guess fields in the MASS preprocessor. In an operational setting,
MASS would likely be configured to run on a redundant system and to use alternate first-guess datasets such as eta gridded data. In that case, none of these $45-\mathrm{km}$ forecasts would have been lost.

Figure 8 displays the percentage of failed runs and categorizes the failed runs based on problems with the systems (hardware/software) or data. There were a total of 462 complete $45-\mathrm{km}$ (coarse grid) runs and 440 complete $11-\mathrm{km}$ (fine grid) runs out of a total 548 possible runs. When a coarse-grid run failed, the finegrid run was not executed. At times, the coarse-grid run could be restarted and executed at the time that the fine grid would normally run. As a result, the 

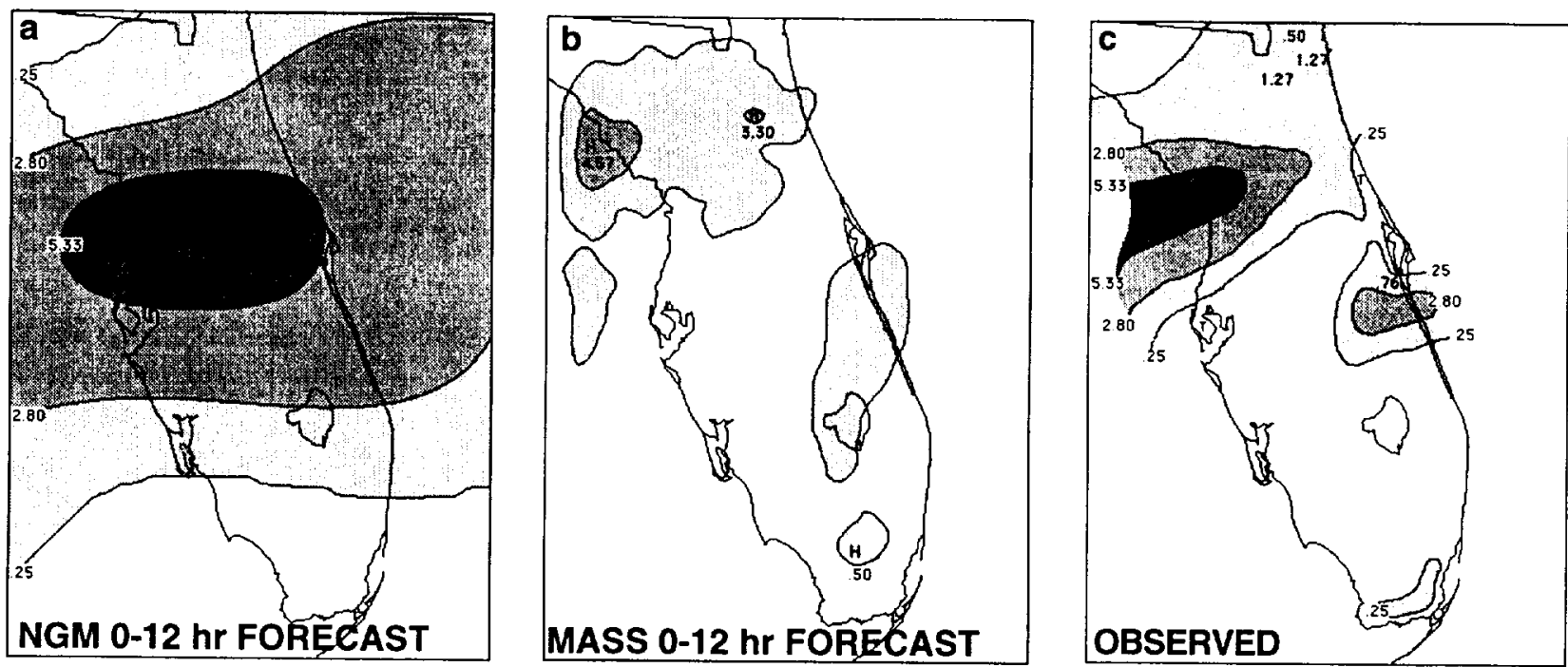

FIG. 7. 12-h accumulated precipitation for the period 1200 UTC 19 February-0000 UTC 20 February from (a) the operational Nested Grid Model, (b) the MASS 11-km model, and (c) an analysis of observed precipitation from first-order and cooperative observing sites. Isopleth interval is $2.54 \mathrm{~mm}$ beginning at $0.25 \mathrm{~mm}$.

number of complete $45-$ and $11-\mathrm{km}$ forecasts do not match exactly.

Figure 8 illustrates that $10.9 \%$ of the coarse runs were lost due to hardware problems, $2.4 \%$ due to software problems, and $2.4 \%$ due to loss of data. The hardware problems were related to disk and power supply failures, while the software problems were related to changing the procedures that handle data processing. The loss of data includes only NGM gridded data that are required as first-guess fields in the MASS preprocessor. Figure 8 also shows that of the 462 complete $45-\mathrm{km}$ runs, 425 (92\%) used NGM analysis grids valid at the time of model initialization, while $37(8 \%)$ used NGM forecast grids from the previous (12-h old) forecast cycle.

\section{b. Computational performance}

An obvious and critical aspect of any real-time numerical forecast system is the requirement for the numerical simulations to be generated quickly enough to be used as a forecast. Currently, it is not possible to simulate satisfactorily, on any computer, all of the significant processes that determine the initiation and evolution of convection over the entire Florida peninsula in real time. Better resolution and greater detail in physics are required than can be selected for real-time simulations on any workstation or supercomputer. The issue is not which computer or network of computers will provide the required level of computational power, but rather, to what level must the simulation model be compromised in order to ex- ecute a real-time numerical forecast at a specified cost. For example, the PSU, CSU, and FSL real-time systems run over very limited domains (Warner and Seaman 1990; Cotton et al. 1994; Snook et al. 1995). At PSU and CSU, grid nesting is used to concentrate the highest horizontal resolution over the local areas of interest. In addition, the version of RAMS at CSU and FSL is run without using explicit microphysics since the scheme greatly increases model run time.

Greater computational power can always be used to improve the quality of the simulations by increasing the horizontal or vertical resolution and using more sophisticated and computationally intensive representations of physical processes. Consequently, the capability of a numerical forecast system is strongly constrained by the power of the computational platform that is available for a specific application. However, the computational power available for a specific price level is rapidly increasing due to continual advances in microprocessor and parallel processing technology. Hence, a workstation-based numerical forecast system should be viewed as a dynamic entity that improves as processing power improves.

The cost constraints on the system designed for $\mathrm{KSC} / \mathrm{CCAS}$ dictated that a moderate-cost computer workstation be used as the computational platform. The selection of the computational platform for the current KSC/CCAS system was made in late 1990. At that time, the Stardent 3000 workstation was an attractive platform for applications, such as MASS, that require high-floating point performance. This 

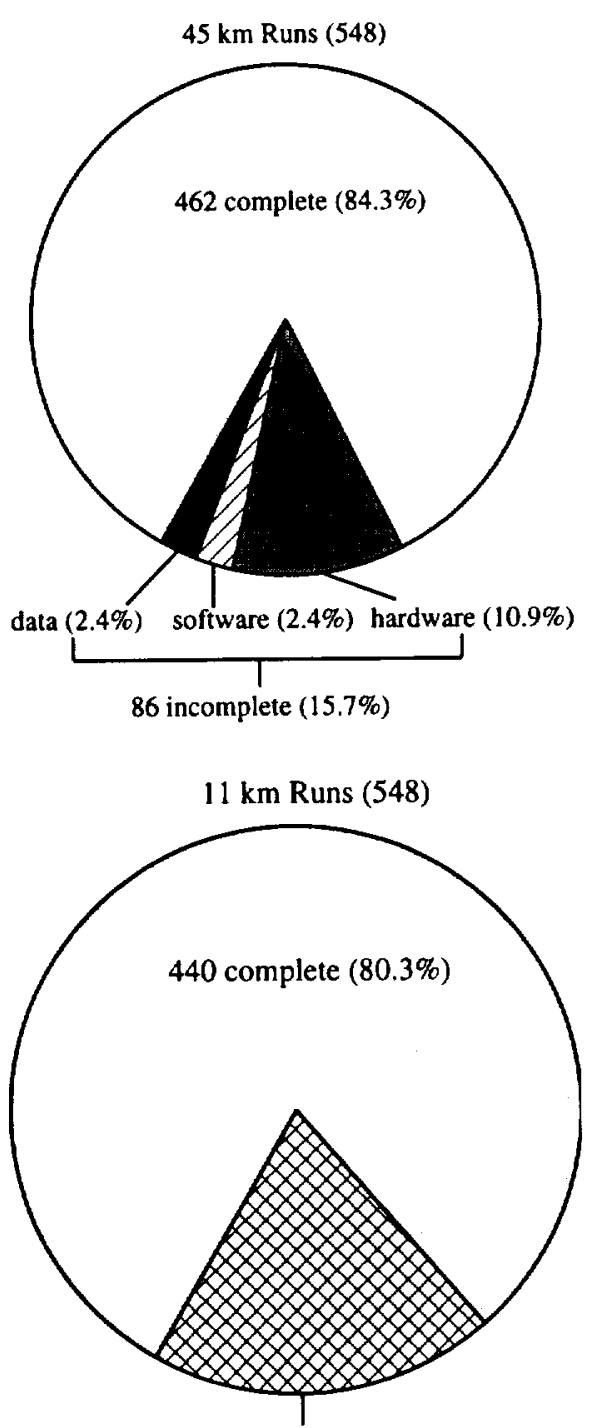

108 incomplete $(19.7 \%)$

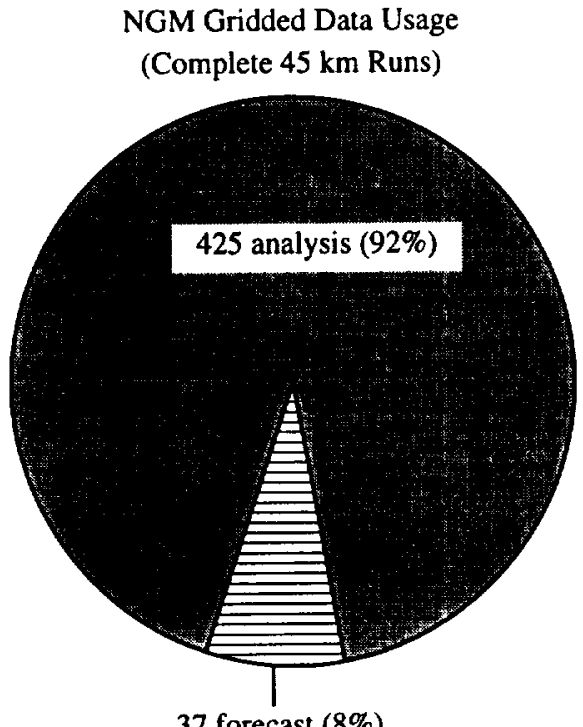

37 forecast $(8 \%)$ system operates at a clock speed of $32 \mathrm{MHz}$ and is capable of achieving a maximum computational rate of 1 floating point operation per clock cycle or 32 million floating point operations per second per CPU board.

Table 4 illustrates the results of MASS computational benchmarks on the 4-CPU Stardent 3000 system and several current workstation systems as well as a Cray 2. Table 4 indicates that the coarsemesh run required just less than $3 \mathrm{~h}$ to execute on the Stardent 3000 system. However, the time on newer computational platforms, which are substantially lower in cost, is about one-third of the Stardent's processing time. For example, the $45-\mathrm{km}$ benchmark simulation executed in $3284 \mathrm{~s}$ (about $55 \mathrm{~min}$ ) on a DEC Alpha Model 3000-600 workstation with a processor clock speed of $175 \mathrm{MHz}$. This is only $26 \%$ longer than the execution time on one processor of a Cray 2 system. Clearly, the era of low-cost desktop supercomputing for numerical weather prediction is here. The DEC Alpha Model 3000-600 has a current list price of about $25 \%$ of the Stardent 3000's 1990 cost. A similar acceleration in performance is evident from the comparison of the $11-\mathrm{km}$ simulations shown in Table 4. These results indicate that a similar model configuration can be executed much more quickly and at a substantially lower cost. Also, a much more sophisticated model can now be executed in the same time and at a lower cost than was possible five years ago.

\section{c. Statistical verification}

The AMU is completing a detailed evaluation of MASS using the nine-month archive (January-October 1994) of twice-daily runs. The evaluation includes objective verification of both gridded and point (or station) forecasts, subjective or phenomenological verification focusing on selected case studies, and rederivation and validation of the LDFs as described in section 2c. The results of the complete evaluation will be presented in a future paper. This subsection highlights two components of the objective verification.

The analyses and forecast fields from all available coarse-grid, fine-grid, NGM, and persistence forecasts from 15 January 1994 through 15 October 1994 are bilinearly interpolated to the selected rawinsonde

FIG. 8. Pie charts showing the percentage of complete $45-\mathrm{km}$ runs, complete $11-\mathrm{km}$ runs, and the source of first-guess fields used for 45-km MASS initialization with analysis denoting the 0 - $h$ NGM gridded analysis data and forecast denoting the $12-h$ NGM gridded forecast data. 
TABLE 4. CPU time required for the benchmark simulation of the operational configuration of the MASS on different computing platforms. The benchmark configuration is essentially identical to the one that is currently used to generate realtime simulations at KSC/CCAS. The physics in the coarse- and fine-mesh simulations are the same with the exception that the coarse mesh utilizes the diagnostic moisture scheme, whereas the fine mesh uses the prognostic moisture scheme.

\begin{tabular}{lcc}
\hline & $\begin{array}{c}\text { 45-km coarse mesh: } \\
\text { 24-h simulation } \\
\text { Computer system }\end{array}$ & $\begin{array}{c}\text { 11-km fine mesh: } \\
\text { 12-h simulation } \\
\text { (matrix size: } \mathbf{5 5} \times \mathbf{5 0 \times 2 0})\end{array}$ \\
\hline Cray 2 (1 CPU) & $2600 \mathrm{~s}$ & $3951 \mathrm{~s}$ \\
DEC Alpha 3000-600 & $\mathbf{3 2 8 4} \mathrm{s}$ & $\mathbf{5 3 6 9 \mathrm { s }}$ \\
IBM RISC 6000/390 & $3227 \mathrm{~s}$ & $5483 \mathrm{~s}$ \\
IBM RISC 6000/560 & $\mathbf{6 2 9 3 \mathrm { s }}$ & $10416 \mathrm{~s}$ \\
Stardent 3000 (4 CPU) & $9718 \mathrm{~s}$ & $15628 \mathrm{~s}$ \\
\hline
\end{tabular}

would be unrealistic to expect that further substantial improvement in temperature forecasts could be diagnosed with rawinsonde data. The similarity in the error characteristics of the two models is not surprising since the NGM provides lateral boundary conditions for the coarse grid, and the coarse grid provides lateral boundary conditions for fine grid. Under strong inflow conditions, the information introduced at the lateral boundary of the coarse- or fine-grid domains can impact the forecasts in a relatively short time period.

The horizontal grid resolution and physical parameterizations in MASS are likely insufficient to produce highly accurate, point-specific forecasts in time or space of warm-seastation locations at West Palm Beach (PBI), Florida; Tampa Bay (TBW), Florida; and Cape Canaveral (XMR), Florida (see Fig. lb for the location of these rawinsonde sites). The average bias and root-meansquare errors (rmse) are computed from the twicedaily (0000 and 1200 UTC) rawinsonde observations of temperature, relative humidity, wind speed, and wind direction at 850,500 , and $300 \mathrm{mb}$. The errors at each pressure level and forecast time are averaged for all three stations at both 0000 and 1200 UTC verifying times over the entire 9 -month period. The rmse at 0,12 , and $24 \mathrm{~h}$ are given in Table 5 .

The MASS model coarse- and fine-grid analysis rmse for temperature and wind speed are typically smaller than those from the NGM, indicating that the MASS analysis scheme fits the rawinsonde data more closely (Table 5). At 12 and $24 \mathrm{~h}$, the errors in the NGM and MASS forecasts for temperature, relative humidity, and wind speed and direction at 850,500, and $300 \mathrm{mb}$ are similar in magnitude (Table 5). Additionally, an examination of the temperature, wind, and moisture bias from the 11- and 45-km MASS model forecasts at these same rawinsonde sites (not shown) does not reveal any serious systematic errors. In general, MASS predicts the large-scale features that are sampled by twice-daily rawinsonde observations as well as the NGM. Furthermore, the magnitude of the errors for both the NGM and MASS are close to the rawinsonde temperature and wind speed measurement uncertainty of about $0.6^{\circ}$ and $3.1 \mathrm{~m} \mathrm{~s}^{-1}$, respectively (Schwartz and Benjamin 1995). Thus, it son convective precipitation. However, to determine how well MASS predicts precipitation, both the coarse- and fine-grid precipitation forecasts over the Florida peninsula are verified using hourly precipitation data collected by the rain gauge network from the St. Johns River, Southwest Florida, and South Florida Water Management districts and the gauges distributed around KSC/CCAS. The average distance between rain gauges is approximately $10 \mathrm{~km}$. The precipitation data are analyzed to the $11-$ and $45-\mathrm{km}$ model grids using a two-pass Barnes (1964) scheme. The hourly gridded precipitation analyses and MASS precipitation forecasts are then summed over $12 \mathrm{~h}$ and compared using the equitable threat score (ETS; Gandin and Murphy 1992).

The 0-12-h ETS from 1200 UTC $11-\mathrm{km}$ runs and 12-24-h ETS from 0000 UTC 45-km runs for each precipitation category and month from January through October 1994 are shown as bar graphs in Fig. 9. [Note that the $0-12-\mathrm{h} 11-\mathrm{km}$ forecasts initialized at 1200 UTC and $12-24-\mathrm{h} 45-\mathrm{km}$ forecasts initialized at 0000 UTC are both valid for the same time period from 1200 through 0000 UTC (see Fig. 2).] The coarse- and fine-grid ETS are less than or equal to 0.5 for all thresholds and months (Figs. 9a,b). For the most part, fine-grid ETS are larger than coarsegrid ETS at thresholds of $2.54,6.35$, and $12.7 \mathrm{~mm}$ indicating that the $11-\mathrm{km}$ runs are consistently better than $45-\mathrm{km}$ runs in predicting precipitation from January through October 1994. In general, the ETS from 11- and 45-km runs from January through May are 
TABLE 5. Rmse in temperature $\left({ }^{\circ} \mathrm{C}\right)$, relative humidity $(\%)$, wind speed $\left(\mathrm{m} \mathrm{s}^{-1}\right)$, and wind direction (degrees) at 300,500 , and $850 \mathrm{mb}$ for MASS coarse-grid (MASS-C), MASS fine-grid (MASS-F), NGM, and persistence (PERSIS) forecasts. Note that persistence errors are computed only at 12 and $24 \mathrm{~h}$, while fine-grid forecast errors are computed only at 0 and $12 \mathrm{~h}$.

\begin{tabular}{|c|c|c|c|c|c|c|c|c|c|}
\hline \multirow{2}{*}{$\begin{array}{c}\text { Forecast } \\
\text { hour }\end{array}$} & \multirow{2}{*}{$\begin{array}{l}\text { Pressure } \\
\text { level (mb) }\end{array}$} & \multicolumn{4}{|c|}{ Rmse in temperature $\left({ }^{\circ} \mathrm{C}\right)$} & \multicolumn{4}{|c|}{ Rmse in relative humidity $(\%)$} \\
\hline & & MASS-C & MASS-F & NGM & PERSIS & MASS-C & MASS-F & NGM & PERSIS \\
\hline \multirow{3}{*}{0} & 300 & 0.5 & 0.4 & 1.2 & - & 12.8 & 12.9 & 18.4 & - \\
\hline & 500 & 0.5 & 0.4 & 1.1 & - & 12.5 & 14.2 & 12.8 & - \\
\hline & 850 & 0.5 & 0.4 & 0.9 & - & 9.2 & 10.7 & 8.4 & - \\
\hline \multirow{3}{*}{12} & 300 & 1.3 & 1.4 & 1.2 & 1.2 & 17.1 & 19.8 & 26.5 & 17.9 \\
\hline & 500 & 1.2 & 1.4 & 1.0 & 1.1 & 19.0 & 22.0 & 21.1 & 22.8 \\
\hline & 850 & 0.9 & 1.0 & 1.2 & 1.1 & 15.7 & 17.8 & 14.8 & 17.1 \\
\hline \multirow{3}{*}{24} & 300 & 1.5 & - & 1.2 & 1.4 & 17.7 & - & 30.8 & 18.8 \\
\hline & 500 & 1.4 & - & 1.1 & 1.4 & 20.8 & - & 22.5 & 26.6 \\
\hline & 850 & 1.0 & - & 1.4 & 1.3 & 17.7 & - & 16.6 & 18.2 \\
\hline
\end{tabular}

larger than those from June through October (Fig. 9). This result suggests that the MASS model provides more accurate explicit precipitation forecasts when synoptic-scale systems and nonconvective precipitation dominate the weather in Florida.

The ETS from 45- and 11-km MASS runs are very similar to those published for operational models such as the NGM and eta model (Junker et al. 1989; Zupanski and Mesinger 1995). However, it is important to point out that the skill scores such as the ETS do not account for the spatial or temporal errors in precipitation forecasts (Olson et al. 1995). For example, the model may predict the correct amount of precipitation $2 \mathrm{~h}$ later and one grid point farther west than observed. In this case, the ETS score would indicate little or no skill in predicting the event, whereas the actual utility of the forecast may be quite good considering the spatial and temporal displacement of forecast precipitation.

\section{Summary and discussion}

This paper describes the general capabilities and operational utility of a version of the MASS that has been developed to support operational weather forecasting at KSC/CCAS. For this application, MASS has been modified to run on workstation-class computers. The motivation for running mesoscale modeling systems like MASS locally at $\mathrm{KSC} / \mathrm{CCAS}$ is to provide detailed short-range $(<24 \mathrm{~h})$ guidance for forecasts of winds, clouds, and severe weather such as thunderstorms. Forecasting these parameters is important for daily operations, and manned and unmanned launches and is a challenging task because the weather during the warm season at KSC/CCAS is dominated by local sea and river breezes, thunderstorm outflows, gust fronts, etc. that are forced by regional and local factors (i.e., land-water boundaries, vegetation type and amount, soil moisture, etc.).

The present version of the MASS forecast system consists of an initialization module, a dynamical model, and a set of statistical models that generate probability forecasts of specific weather events from MASS model output and observations. The AMU has been running MASS twice-daily on a Stardent 3000 workstation since January 1994 and archiving both model output and observations for the purpose of model evaluation. During the nine-month period from 15 January 1994 to 15 October 1994, the largest percentage (10.9\%) of missed runs resulted from hardware failures. In an operational setting, MASS would likely run on a redundant system, which could have prevented these lost runs. Overall, no model forecasts were lost due to instabili- 
TABLE 5. (Continued)

\begin{tabular}{|c|c|c|c|c|c|c|c|c|c|}
\hline \multirow{2}{*}{$\begin{array}{c}\text { Forecast } \\
\text { hour }\end{array}$} & \multirow{2}{*}{$\begin{array}{l}\text { Pressure } \\
\text { level }(\mathrm{mb})\end{array}$} & \multicolumn{4}{|c|}{ Rmse in wind speed $\left(\mathrm{m} \mathrm{s}^{-1}\right)$} & \multicolumn{4}{|c|}{ Rmse in wind direction (degrees) } \\
\hline & & MASS-C & MASS-F & NGM & PERSIS & MASS-C & MASS-F & NGM & PERSIS \\
\hline \multirow{3}{*}{0} & 300 & 1.4 & 1.7 & 2.3 & - & 8.5 & 13.2 & 12.7 & - \\
\hline & 500 & 1.1 & 1.4 & 1.9 & - & 9.8 & 17.3 & 14.2 & - \\
\hline & 850 & 1.0 & 1.5 & 1.6 & - & 13.0 & 26.3 & 18.9 & - \\
\hline \multirow{3}{*}{12} & 300 & 3.3 & 3.6 & 3.5 & 4.5 & 19.6 & 22.9 & 22.4 & 28.3 \\
\hline & 500 & 2.6 & 2.9 & 2.9 & 3.3 & 22.9 & 23.8 & 22.6 & 32.8 \\
\hline & 850 & 2.2 & 2.3 & 2.4 & 2.8 & 35.2 & 41.5 & 30.4 & 46.4 \\
\hline \multirow{3}{*}{24} & 300 & 3.6 & - & 3.7 & 5.8 & 22.0 & - & 23.5 & 37.2 \\
\hline & 500 & 2.9 & - & 3.2 & 4.2 & 24.9 & - & 25.1 & 36.0 \\
\hline & 850 & 2.4 & - & 2.6 & 3.4 & 39.3 & - & 35.8 & 53.9 \\
\hline
\end{tabular}

ties generated by the model's physics or dynamics or problems with the model or data preprocessor software suggesting that MASS is extremely robust and would be a very reliable operational system.

The AMU is completing a detailed evaluation of MASS that includes objective verification, case studies, and recomputation of the LDFs. A brief examination of rmse for temperature, wind, and moisture from MASS versus the NGM at selected rawinsonde stations over all available cases during the nine-month archiving period reveals that MASS is predicting the large-scale features as well as the NGM. This result is expected since the NGM provides lateral boundary conditions for the $45-\mathrm{km}$ MASS runs. In fact, verification of parameters whose variance is dominated by large-scale processes is unlikely to reveal a large improvement by mesoscale models such as MASS since much of the variance is already accounted for by regional-scale models such as the NGM. However, to illustrate the utility of running MASS at $11 \mathrm{~km}$ over the Florida peninsula, a case is presented comparing the forecast guidance available from MASS versus that from the NGM during 19 February 1992 when mesoscale circulations were an important contributor to the initiation and evolution of convective storms. The performance of the 11-km MASS run for this case, while not spectacular, was superior to the $80-\mathrm{km}$ NGM forecast especially with respect to the distribution of precipitation.
Although the precipitation forecasts for the one case presented here are superior to those from the NGM and are reasonable in a qualitative sense, it is important to quantify how well MASS predicts precipitation from the $45-$ and $11-\mathrm{km}$ runs over many cases. For this purpose, the AMU verified precipitation forecasts from MASS using rain gauge data with roughly $10-\mathrm{km}$ spacing over the Florida peninsula. The ETS derived from $1200 \mathrm{UTC} 11 \mathrm{~km}$ runs and 0000 UTC $45-\mathrm{km}$ runs for January through October 1994 are less than 0.5 and are not consistently better than those reported for operational models such as the NGM and eta. However, MASS does show greater skill as evidenced by higher ETS from January through May 1994. It is well known that operational models such as the NGM show less skill in forecasting warm season precipitation associated with smallscale convective-type weather systems (Junker et al. 1989; Olson et al. 1995).

Based on the ETS derived from mesoscale precipitation data for MASS model runs, it is apparent that precipitation forecasting remains a problem for mesoscale models, especially in a subtropical environment characterized by weak large-scale forcing such as Florida in the warm season. The fact that the $11-\mathrm{km}$ MASS runs do not show more skill than operational models in forecasting warm season precipitation is likely due to a number of factors including insufficient horizontal resolution and deficiencies in the 

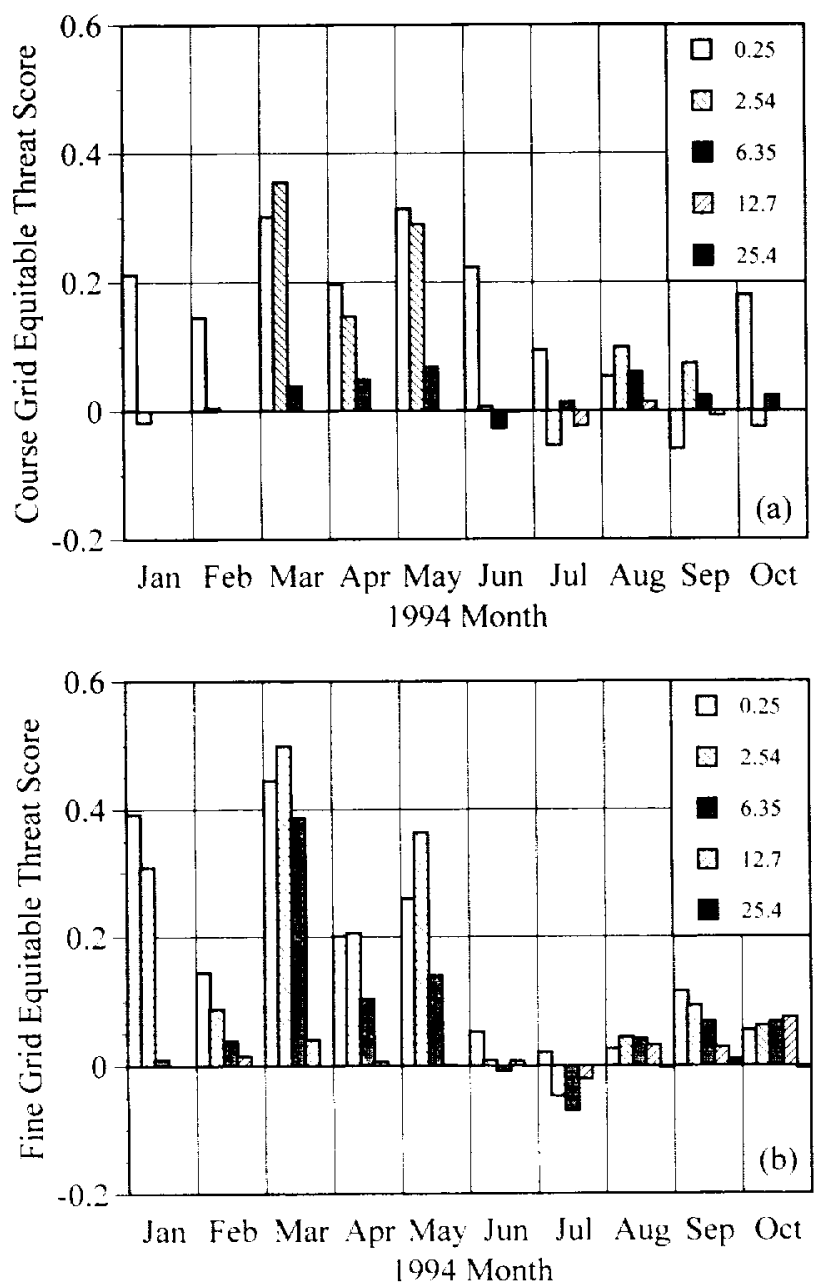

Fici. 9. Equitable threat scores for all $11-k m$ MASS runs initialized at 1200 UTC and for all 12-24-h forecasts from 45-km MASS runs initialized at 0000 [TC during January through Oetober 1994. The ETS for precipitation thresholds of 0.25, 2.54 . 6.35 .12 .7 and $25.4 \mathrm{~mm}$ from the $4.5-\mathrm{km}$ coarse-grid forecasts are shown in panel (al. while those from the $11-\mathrm{km}$ fine-grid forecasts are shown in panel (b).

physical parameterizations. especially the KuoAnthes convective scheme. In addition, the components of the surface energy budget such as evapotranspiration and the representation of the existence and impact of subgrid-scale clouds are simplified so that MASS can run in real time on workstations. Finally, it is difficult to specify accurate mesoscale distributions of atmospheric moisture (including clouds and preexisting convection), temperature. winds, and moisture in the soil and surface cover layer from the data sources currently used in MASS. The data available from the WSR-88D radars, Doppler wind profilers, the new series of geostationary satellites (GOES-I, J), and Global Positioning System sat- ellites (Bevis et al. 1992; Chiswell et al. 1994) may offer an opportunity to improve initialization and short-range forecasts by MASS if they can be incorporated into the system in real time.

Workstation-based, real-time numerical modeling systems must run fast enough so that the forecasts can be used before they expire. However, this obvious and critical aspect of these systems must be balanced against the desire to improve the quality of the simulations by increasing the horizontal and/or vertical resolution and using more sophisticated physical parameterizations. The choice of model attributes such as physics, domain size and extent, number of grid nests, resolution, and forecast length is highly constrained by available computational resources for applications of workstation-based real-time modeling systems. Clearly, the era of affordable, real-time numerical weather prediction on workstations has arrived. Since the monetary cost of computational power continues to decrease with further advances in microprocessor and parallel processing technology, there is still opportunity for rapid advancement in model performance. Hence, a workstation-based numerical forecast system should be viewed as a dynamic entity and should evolve in tandem with the processing power available al a specified cost.

In closing, it is important to reiterate that MASS is not yet an operational system. The AMU has been sending real-time MASS output to meteorologists and forecasters at the RWO, SMG. and NWS since March 1995. As potential end users of model products. their feedback to the AMU regarding whether MASS provides value-added information to the analysis and forecasting of warm season weather at $\mathrm{KSC} / \mathrm{CCAS}$ is a very important component of the overall system evaluation. The ultimate recommendation to transition MASS for operational use will depend on forecaster feedback and the final results of the AMU's evaluation of MASS. If the recommendation is made to transition MASS, there are a number of outstanding issues involved in the process including documentation, system certification, training. and life-cycle costs (i.e., who pays to maintain. repair, and potentially upgrade the hardware and software). It is anticipated that the AMU will play an integral role in developing a transition strategy that addresses these concerns. Furthermore, a transition of MASS into operations at KSC/CCAS will require close coordination among the AMU, the users, and the organizations responsible for certifying and maintaining the USAF Eastern Range assets. 
Acknowledgments. The authors gratefully acknowledge AMU staff member Ann Yersavich and MESO, Inc.'s Mary Bousquet for their assistance in figure preparation and manuscript review. The authors also thank Drs. F. Merceret (NASA KSC) and J. Ernst (NASA HQ), Ms. R. Schumann (AMU), Mr. B. Boyd (USAF 45 WS), Major R. Thorp (USAF 45 WS), Mr. D. Sharp (NWS MLB), Mr. D. Petersen (NWS MLB), Mr. F. Brody (SMG), Mr. R. Lafosse (SMG), and Mr. T. Oram (SMG) for their comments and suggestions on an earlier version of the manuscript. The authors greatly appreciate Dr. Merceret's suggestion to submit the Delta II lightning strike as a cover photograph. Mr. Charles Thompson (McDonnell Douglas) provided the flight line video that was used by Mr. Brad Lawrence (Lockheed Space Operations Visual Audio Mastering Studio) to generate a digital image of the Delta II lightning strike. Three anonymous reviewers offered very useful comments that improved the paper.

\section{References}

Adler, R. F., and A. J. Negri, 1988: A satellite infrared technique to estimate tropical convective and stratiform rainfall. J. Appl. Meteor., 27, 30-51.

Anderson, J. R., E. E. Hardy, J. T. Roach, and R. E. Witmer, 1976: A land use and land cover classification system for use with remote sensor data. U.S. Geological Survey Professional Paper 964, U.S. Government Printing Office, Washington, DC, $28 \mathrm{pp}$.

Anthes, R. A., 1977: A cumulus parameterization scheme using a one-dimensional cloud model. Mon. Wea. Rev., 105, 270-286.

Barnes, S. L., 1964: A technique for maximizing details in numerical weather map analysis. J. Appl. Meteor., 3, 396-409.

Bevis, M., S. Businger, T. Herring, R. A. Anthes, C. Rocken, and R. H. Ware, 1992: Remote sensing of atmospheric water vapor using the global positioning system. J. Geophys. Res., 97, $15787-15801$.

Buzbee, B., 1993: Workstation clusters rise and shine. Science, 261, 852-853.

Chang, J.-T., and P. J. Wetzel, 1991: Effects of spatial variations of soil moisture and vegetation on the evolution of a prestorm environment: A numerical case study. Mon. Wea. Rev., 119, 1368-1390.

Chang, S. W., R. J. Alliss, S. Raman, and J.-J. Shi, 1993: SSM/1 Observations of ERICA IOP 4 marine cyclone: A comparison with in situ observations and model simulation. Mon. Wea. Rev., 121, 2452-2464.

Chiswell, S. R., S. Businger, and M. Bevis, 1994: Improved retrieval of integrated water vapor from vapor radiometer measurements using numerical weather prediction models. J. Atmos. Oceanic Technol., 11, 1253-1261.

Cotton, W. R., G. Thompson, and P. W. Mielke Jr., 1994: Realtime mesoscale prediction on workstations. Bull. Amer. Meteor. Soc., 75, 349-362.

Cram, J. A., R. A. Pielke, and W. R. Cotton, 1992: Numerical simulation and analysis of a prefrontal squall line. Part I: Observations and basic simulation results. J. Atmos. Sci., 49, 189-208.
Doyle, J. D., and T. T. Warner, 1993a: A numerical investigation of coastal frontogenesis and mesoscale cyclogenesis during GALE IOP 2. Mon. Wea. Rev., 121, 1048-1077.

$\longrightarrow$, and $\_, 1993 \mathrm{~b}$ : Nonhydrostatic simulations of coastal mesobeta-scale vortices and frontogenesis. Mon. Wea. Rev:. 121, 3371-3392.

Dudhia, J., 1993: A nonhydrostatic version of the Penn State-NCAR mesoscale model: Validation tests and simulation of an Atlantic cold front. Mon. Wea. Rev., 121, 1493-1513.

Fischer, R. A., 1938: The statistical utilization of multiple measurements. Ann. Eugenics, 8, 376-386.

Flatau, P. J., G. J. Tripoli, J. Verlinde, and W. R. Cotton. 1989: The CSU-RAMS cloud microphysics module: General theory and code documentation. Atmos. Sci. Paper 451, Colorado State University, 88 pp. [Available from Department of Atmospheric Science, Colorado State University, Fort Collins, CO 80523.]

Frank, W. M., and C. Cohen, 1987: Simulation of tropical convective systems. Part I: A cumulus parameterization. J. Atmos. Sci., 44, 3787-3799.

Fritsch, J. M., and C. F. Chappell, 1980: Numerical prediction of convectively driven mesoscale pressure systems. Part I: Convective parameterization. J. Atmos. Sci., 37, 1722-1733. Gandin. L. S., 1963: Objective analysis of meteorological fields. Hydrometeorological Publishing House, 242 pp.

_- and A. S. Murphy, 1992: Equitable skill scores for categorical forecasts. Mon. Wea. Rev, 120, 361-370.

Holt, T., S. W. Chang, and S. Raman, 1990: A numerical study of the coastal cyclogenesis in GALE IOP 2: Sensitivity to PBL parameterization. Mon. Wea. Rev., 118, 234-257.

Junker, N. W., J. E. Hoke, and R. H. Grumm, 1989: Performance of NMC's regional models. Wea. Forecasting, 4, 368-390.

Kaplan, M. L., J. W. Zack, V. C. Wong, and J. J. Tuccillo, 1982: Initial results from a mesoscale atmospheric simulation system and comparisons with the AVE-SESAME I data set. Mon. Wea. Rev., 110, 1564-1590.

,,--- , and -1985 : The interactive role of subsynoptic scale jet streak and planetary boundary layer adjustments in organizing an isolated convective complex. Mon. Wea. Rev.. 113, 2212-2238.

Kuo, H. L., 1965: On the formation and intensification of tropical cyclones through latent heat release by cumulus convection. J. Aimos. Sci., 22, 40-63.

- 1974: Further studies of the parameterization of the influence of cumulus convection on large-scale flow. J. Atmos. Sci., 31, 1232-1240.

Kuo, Y.-H., R. J. Reed, and S. Low-Nam, 1992: Thermal structure and airflow in a model simulation of an occluded marine cyclone. Mon. Wea. Rev., 120, 2280-2297.

Lyons, W. L., C. J. Tremback, R. L. Walko, R. A. Pielke, and W. R. Cotton, 1994: Design of an operational forecasting system for localized and sea breeze thunderstorms at the Kennedy Space Center. Preprints, IOth Int. Conf. on Interactive Information Processing for Meteorology, Oceanography, and Hydrology, Nashville, TN, Amer. Meteor. Soc., 213-218.

Mahrer, Y., and R. A. Pielke, 1977: A numerical study of the airflow over irregular terrain. Beitr. Phys. Atmos., 50, 98-113.

Mahrt, L., and H. Pan, 1984: A two-layer model of soil hydrology. Bound-Layer Meteor., 29, 1-20. 
Manobianco, J.. L. W. Uccellini, K. F. Brill, and P. J. Kocin, 1991: Contrasting the impact of dynamic data assimilation on the numerical simulation of cyclogenesis during GALE IOP 10 and 1. Meteor. Atmos. Phy., 45, 41-63.

_, S. Koch, M. Karyampudi, and A. J. Negri, 1994: The impact of assimilating satellite-derived precipitation rates on numerical simulations of the ERICA IOP 4 cyclone. Mon. Wea. Re'i'., 122, 341-365.

McCumber, M. C., and R. A. Pielke, 1981: Simulation of the effects of surface fluxes of heat and moisture in a mesoscale numerical model. Part I: Soil layer. J. Geophys. Res., 86, 9929-9938.

MESO, 1993: MASS version 5.6 reference manual. $118 \mathrm{pp}$. |Available from MESO, Inc., 185 Jordan Road, Troy, NY 12180.]

Noilhan, J., and S. Planton, 1989: A simple parameterization of land surface processes for meteorological models. Mon. Wea. Rev., 117, 536-549.

Olson, D. A., N. W. Junker, and B. Korty, 1995: Evaluation of 33 years of quantitative precipitation forecasting at NMC. Wea. Forecasting, 10, 498-511.

Orlanski, I., 1976: A simple boundary condition for unbounded hyperbolic flows. J. Comput. Phys., 21, 251-269.

Perkey, D. J.. and C. W. Kreitzberg, 1976: A time-dependent lateral boundary scheme for limited-area primitive equation models. Mon. Wea. Rev., 104, 745-755.

Pielke, R. A., 1974: A three-dimensional numerical model of the sea breezes over south Florida. Mon. Wea. Rev., 102, 115-134.

—, G. Dalu, J. S. Snook, T. J. Lee, and T. G. F. Kittel, 1991: Nonlinear influence of mesoscale land use on weather and climate. J. Climate, 4, 1053-1069.

Sasamori, T., 1968: Radiative cooling calculation for application to general circulation experiments, J. Appl. Meteor., 7, $721-729$.

Savijarvi, H., 1990: Fast radiation parameterization schemes for mesoscale and short-range forecast models. J. Appl. Meteor., 29, 437-447.

Schwartz, B., and S. G. Benjamin, 1995: A comparison of temperature and wind measurements from ACARS-equipped aircraft and rawinsondes. Wea. Forecasting, 10, 528-544.

Smagorinsky, J., 1963: General circulation experiments with the primitive equations. Part I: The basic experiment. Mon. Wea. Rev., 91, 99-164.

Snook, J. S., J. M. Cram, and J. M. Schmidt, 1995: LAPS/RAMS. A nonhydrostatic mesoscale modeling system configured for operational use. Tellus, 47A, 864-875.

Stauffer, D. R., and N. L. Seaman, 1990: Use of four-dimensional data assimilation in a limited area mesoscale model. Part I: Experiments with synoptic-scale data. Mon. Wea. Rev., 118, 1250-1277.

$\longrightarrow,-$ and F. S. Binkowski, 1991: Use of four-dimensional data assimilation in a limited area mesoscale model. Part II: Effects of data assimilation within the planetary boundary layer. Mon. Wea. Rev., 119, 734-754.
Stephens, G. L., 1978: Radiation profiles in extended water clouds. Part II: Parameterization schemes. J. Atmos. Sci., 35, 2123-2132.

Thompson, G., 1993: Prototype real-time mesoscale prediction during the 1991-92 winter season and statistical verification of model data. M.S. thesis, Atmos. Sci. Paper No. 521, Colorado State University, $88 \mathrm{pp}$. [A vailable from Department of Atmospheric Science, Colorado State University, Fort Collins, CO 80523.]

Tremback, C. J., W. A. Lyons, W. P. Thorson, and R. L. Walko, 1994: An emergency response and local weather forecasting software system. Preprints, Eighth Joint Conf. on the Applications of Air Pollution Meteorology, Nashville. TN, Amer. Meteor. Soc., 219-223.

Uccellini, L. W., R. A. Petersen, K. F. Brill, P. J. Kocin, and J. J. Tuccillo, 1987: Synergistic interactions between an upper-level jet streak and diabatic processes that influence the development of a low-level jet and secondary coastal cyclone. Mon. Wea. Rev., 115, 2227-2261.

Warner, T. T., and N. L. Seaman, 1990: A real-time, mesoscale numerical weather-prediction system used for research, teaching, and public service at The Pennsylvania State University. Bull. Amer. Meteor. Soc., 71, 792-805.

Xian, Z., and R. A. Pielke, 1991: The effects of width of land masses on the development of sea breezes. J. Appl. Meteor., 30, 1280-1304.

Young, S. H., and J. W. Zack, 1994: The use of nonstandard data to improve the initialization of relative humidity in mesoscale models. Preprints, 10th Conf. on Numerical Weather Prediction. Portland, OR, Amer. Meteor. Soc., 326-327.

Zack, J. W., and M. L. Kaplan, 1987: Numerical simulations of the subsynoptic features associated with the AVE-SESAME I Case. Part I: The preconvective environment. Mon. Wea. Rev., 115, 2367-2394.

- K. T. Waight, S. H. Young, M. Ferguson, M. D. Bousquet, and P. E. Price, 1993: Development of a mesoscale statistical thunderstorm prediction system. Final report to NASA under Contract NAS10-11670, 203 pp. [Available from MESO, Inc., 185 Jordan Road, Troy, NY 12180.|

Zhang, D.-L., 1989: The effect of parameterized ice microphysics on the simulation of vortex circulation with a mesoscale hydrostatic model. Tellus, 41A, 132-147.

- - and R. A. Anthes, 1982: A high resolution model of the planetary boundary layer-sensitivity tests and comparisons with SESAME-79 data. J. Appl. Meteor., 21, 1594-1609.

- and J. M. Fritsch, 1986: Numerical simulation of the meso$\beta$-scale structure and evolution of the 1977 Johnstown flood. Part I: Model description and verification. J. Atmos. Sci., 43, 1913-1943.

Zupanski, D., and F. Mesinger, 1995: Four-dimensional variational assimilation of precipitation data. Mon. Wea. Rev., 123, 1112-1127. 



\section{on the cover}

Delta II rocket with Global Positioning Satellite payload on Launch Complex 17B at Cape Canaveral Air Station, Florida. The still frame was created from flight line video zoomed in on the pad and captures a cloud-to-ground lightning strike at 2239:04 UTC on 19 February 1992 while the launch count was holding at T-4 minutes. The lightning strike occurred offshore about $8 \mathrm{~km}$ to the northeast of the pad in association with an area of thunderstorms (see case example in the article by Manobianco et al. on page 653). 